\title{
الجوانب الإبتكارية فى الأثاث والغرف السرية
}

\section{Innovative aspects in furniture and secret rooms}

م.د/ وسام ممدوح عز الدين الفولى الفي

مدرس بقسم التصميم الداخلى والأثاث ـ كلية الفنون التطبيقية - جامعة بنها

Dr. Wessam Mamdouh Ezzeldin Alfuly

Lecture at faculty of applied arts - Interior design and furniture department - Banha university

wesam.ezzeldeen@gmail.com

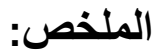

لكل منا أثنياءه الخاصة التى يريد وضعها فى مكان ما لا يصل إليه أحد غيره، وأحيانا تتملكنا الرغبة فى الإختلاء بأنفسنا بعيداً عن صخب العالم؛ لذا يلجأ الكثثرين إلى تصميم غرفاً سرية بالمنزل أو العمل، سو اء للإسترخاء أو للتأمل بهدوء في في الإهي المشكلات أو حتي للجلوس بداخلها للحصول علي المزيد من الترفيه والإستمتاع بالخصوصية، هذه الغرف السرية يتم

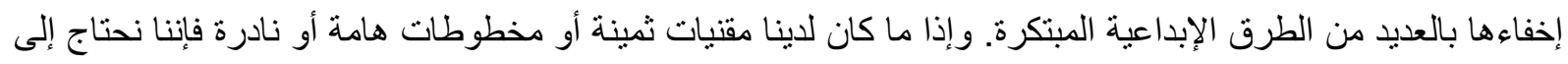

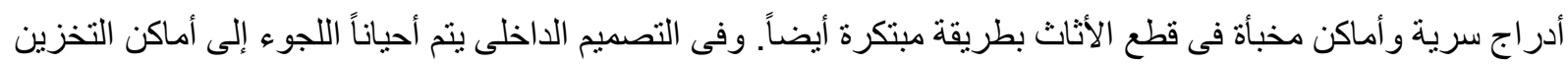
المخبأة لأغر اض جمالية بهدف إخفاء بعض عيوب التصميم داخل الفر اغات المعمارية. وقد ساعدت التكنولوجيا الحديثة فى ابتكار العديد من الطرق والأساليب المتعددة لتصميم مداخل تلاك الغرف السرية وتأمينها ووضع الحلول التصميمية لإخفاء بعض أماكن التخزين داخل قطع الأثاث المتتوعة. ونحن بحاجة إلى مثل هذه الدر اسات لمواجهة بعض التحديات فى ظل الألفية الثالثة؛ لذا جاءت فكرة البحث للتركيز على تلك الجوانب والحلول التصميمية

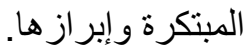
و على مدى تاريخ البشرية كانت فكرة الغرف السرية وأماكن التخزين المخبأة دائما ما كانت جاذبة ومثيرة للإهنمام، وقد ذاع انتشارها عبر مر احل التاريخ المختلفة؛ فقد وجدت مثل هذه الغرف والدهاليز فى العصور القديمة كمنازل الزعماء وذوى النفوذ والأغنياء، وتعددت أسباب تصميمها من كونها مأمن او لمواجهة الظروف الطارئة أو اللجوء إليها فى حالة

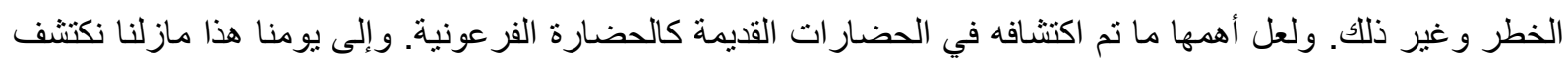

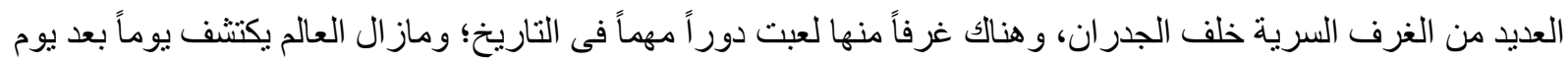

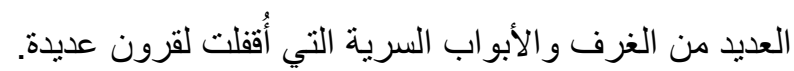

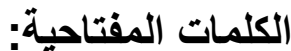
الغرف السرية؛ الأثاث السري؛ الجوانب الإبتكارية؛ الحلول التصميمية؛ الأبواب السرية

\section{Abstract:}

Each of us has his own things that he wants to put in a place that no one else can reach, and sometimes we have the desire to be alone, away from the hustle and bustle of the world; Therefore, many resorts to designing secret rooms at home or at work, whether to relax or to quietly contemplate problems or even to sit inside to get more entertainment and enjoy privacy, these secret rooms are hidden in many creative and innovative ways. If we have valuable collections or rare important manuscripts, we need secret drawers and hidden places in the furniture in an innovative way as well. In interior design, concealed storage places are 
sometimes used for aesthetic purposes in order to hide some design flaws within the architectural spaces.

Modern technology has helped innovate many ways and methods to design the entrances to these secret rooms, secure them, and develop design solutions to hide some storage places inside the various pieces of furniture. We need such studies to meet some challenges in light of the third millennium. Therefore, the idea of research came to focus on and highlight these aspects and innovative design solutions.

Throughout the history of mankind, the idea of secret rooms and hidden storage places has always been attractive and interesting, and its spread has spread throughout the various stages of history. Such rooms and corridors existed in ancient times as homes of leaders, influential people and the rich, and the reasons for their design varied from being safe, to face emergency conditions, or resorting to them in case of danger and so on. Perhaps the most important of them is what was discovered in ancient civilizations, such as the Pharaonic civilization. And to this day we still discover many secret rooms behind the walls, and there are some of them that played an important role in history. And the world is still discovering, day after day, many secret rooms and doors that have been closed for many centuries.

\section{key words:}

Secret rooms; Secret furniture; Innovative aspects; Design solutions; Secret doors

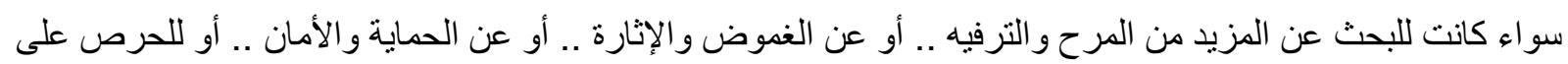

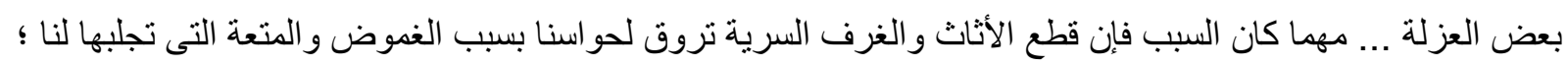
كما أنها طريقة للهروب من صخب العالم و البحث عن الخصوصية والأمان فى الفر اغ الداخلى .... تم استخدام الغرف السرية لعدة قرون.. فى منازل الأثرياء وذوى النفوذ مثل الملوك و الأرستقر اطيين ، تقريباً فى كل قلعة ولهن

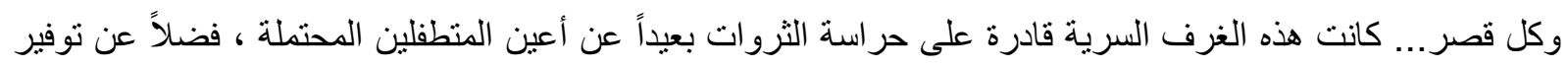

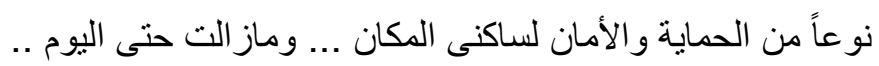

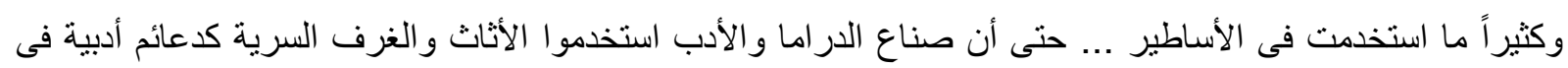
رواياتهم لتساعدهم فى الحبكة الدرامية وتحافظ على النتويق المطلوب و الإثارة... إنها بمثابة حافز يثير العقول الفضولية فى رحلة لمعرفة الأسر ار المخفية خلف الجدران وما وراء التصميم... إنها تمثل تجسيداً لعبارة "أكثر مما تراه العين" ل. ...

و عندما يتبادر إلى أذهانتا فكرة الأثاث و الغرف السرية ليس معنى ذلك أبداً أن الأمر قاصر على حفظ الأوراق و الوثائق و المقتنيات الهامة فحسب ... بل إن إيقاغ الحياة و التحديات التصميمية فرضت نفسها على الو اقع .. فبتنا نبحث عن ملاذ آمن نختلى فيه بأنفسنا قليلاً بعيداً عن الضغوطات اليومية و الصخب ... أو للرغبة فى الإسترخاء وممارسة الهوايات، أو لحماية

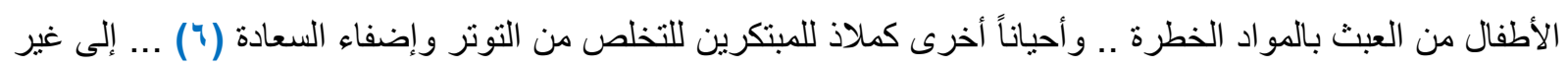
ذلك؛ فالمسألة إذن لم تعد قاصرة على جانب واحد فقط .. فلقد تغير العصر وتطورت معه الكثير من المنطلبات الحياتية .. 
ولما كان التصميم الداخلى هو الميدان الخصب الذى نرصد فيه رحابة التجربة التصميمية ... فإنه من الضرورى أن نكثف

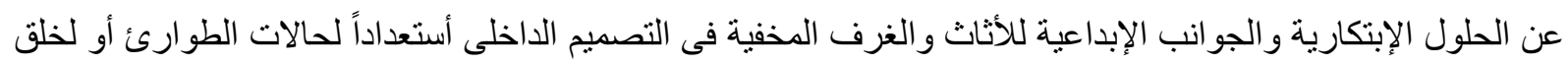

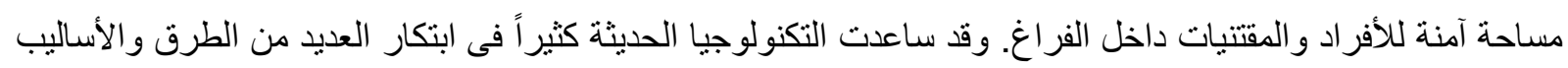
المتعددة لتصميم مداخل تلك الغرف السرية وتأمينها ووضع الحلول التصميمية لإخفاء بعض أماكن التخزين داخل قطع

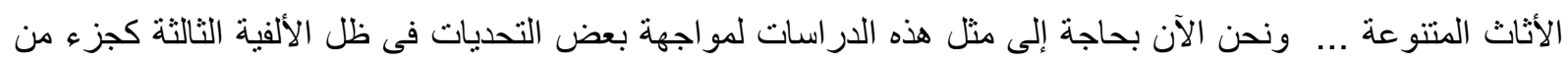
خطة الطو ارئ داخل التصميم؛ لذا جاءت فكرة البحث للتركيز على تلك الجو انب والحلول التصميمية المبتكرة و إبرازها....

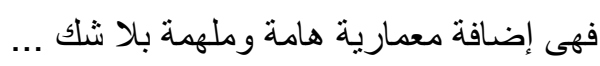

مشكلة البحث: كيفية التوصل الي الحلول الإبتكارية والجوانب الإبداعية للأثاث و الغرف المخفية فى التصميم الداخلى إستعداداً لحالات

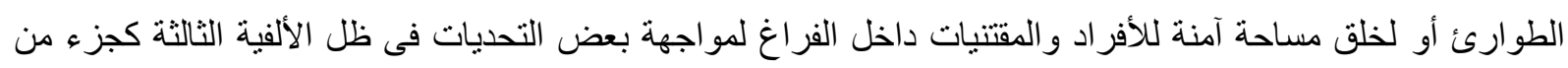
خطة الطو ارئ داخل التصميم. أهمية البحث: 1. إبراز القيم الوظيفية والجمالية المتعددة للأثاث و الغرف السرية. 2. تحديث الرؤية التصميمية تجاه الفراغات المخفية مع نمو الإحتياجات الوظيفية و النفسية للإنسان المعاصر.

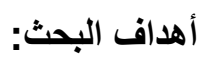
1. الكثف عن أنواع الحيل التصميمية المبنكرة لإخفاء ودمج الفراغات السرية داخل التصميم الداخلى والأثاث. 2. الوصول إلى كيفية خلق مساحات آمنة داخل الفر اغ لتأمين راحة الأفر اد ومقتتياتهم الثمينة و الهامة. 3. در اسة أهم الطرق الإبداعية المتنو عة فى تصميم الأثاث و الغرف السرية. 4. تعظيم الإستفادة من المساحات الداخلية المتوفرة لأغر اض الخصوصية الاثنة أو لإخفاء العيوب داخل التصميم.

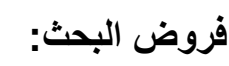
يفترض البحث ان: 1- و وجود أثثاث أو غرف سرية دائماً لا يعني وجود قلق ما فى المكان أو انه غير آمن.

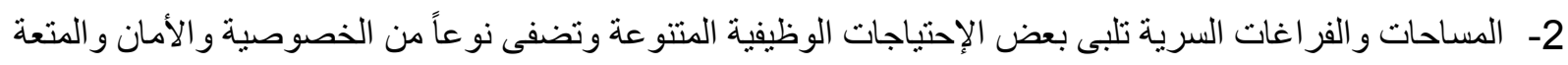
لثناغلى المكان. منهج البحث: المنهج الوصفى التحليلى.

\section{ا - نبذة تاريخية عن الأثاث والغرف السرية:}

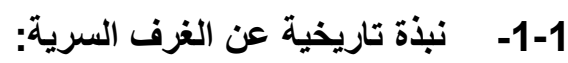

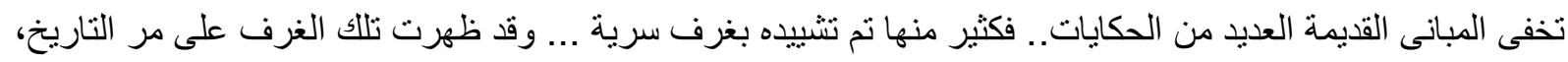

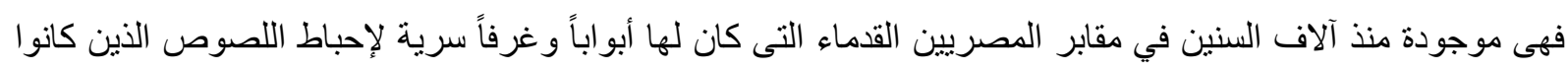

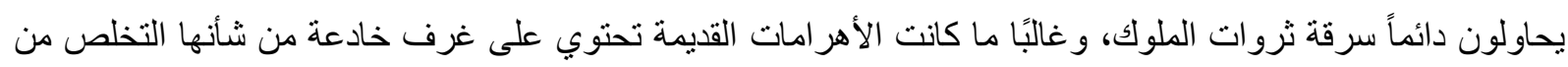

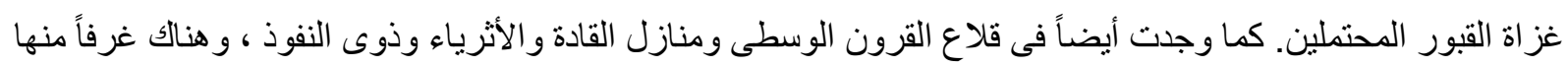
لعبت دور اً مهماً فى التاريخ؛ فكثير اً ما ساعدت تللك الغرف و الممر ات السرية بعض الحكام المحاصرين للهرب من مهاجميهم،

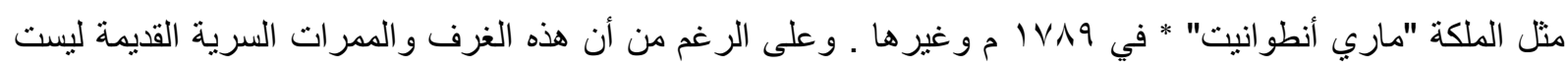

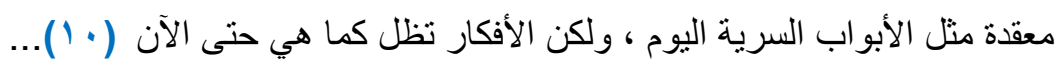



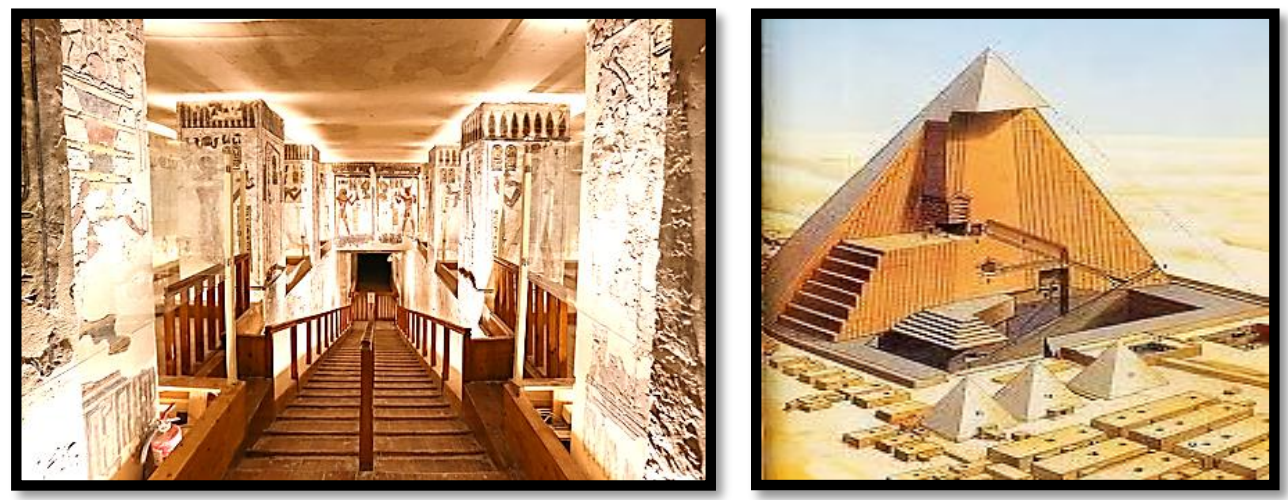

شكل ( 1): الغرف السرية والمداخل الخادعة فى الأهرامات ومقابر المصريين القدماء (1 1)

وفي مطلع القرن العشرين .. خلال فترة حظر المشروبات الكحولية في الولايات المتحدة الأمريكية ، انتشر ظهور الغرف السرية لأولئك الذين يريدون إلى الالتفاف على القانون فى عشرينيات القرن الماضى ... ومع التهديد بشن هجوم نووي على الولايات المتحدة في ستينيات القرن الماضى ؛ بدأت الغرف ذات الأبواب السرية تشق طريقها إلى المنازل

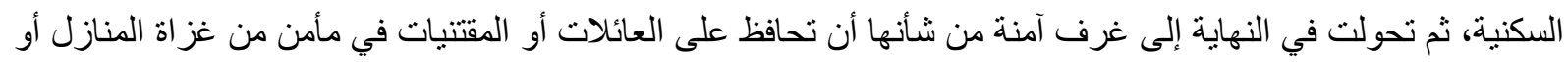

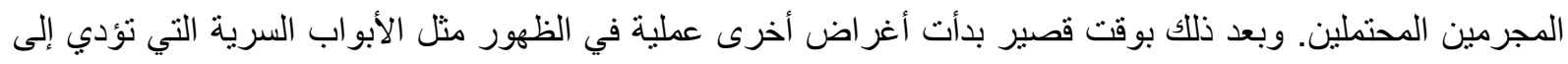

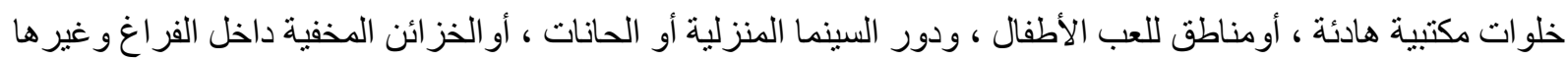

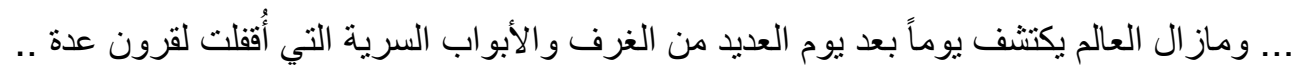

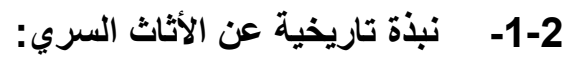
قبل أيام البنوك وصناديق الودائع ، كان الناس غالبة البًا ما يحتفظون بالنقود و المقتنيات الثمينة مخبأة داخل المنزل. لذلك كان

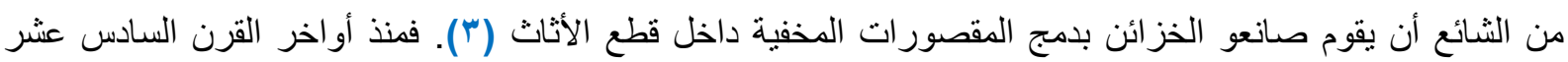

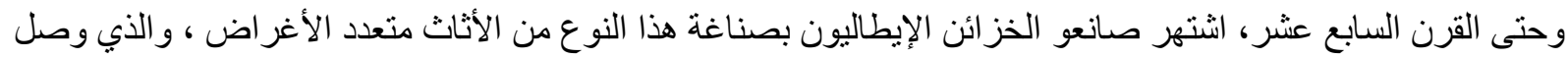

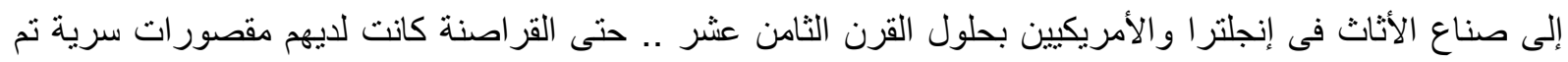

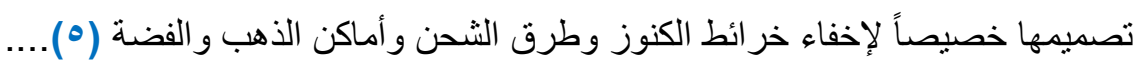
في الوقت الحاضر ، غالبًا ما نعتمد على البنوك أو صناديق الودائع الآمنة لتأمين أمو النا أو ممتلكاتنا الخاصة ، ولكن ونس الأثناث

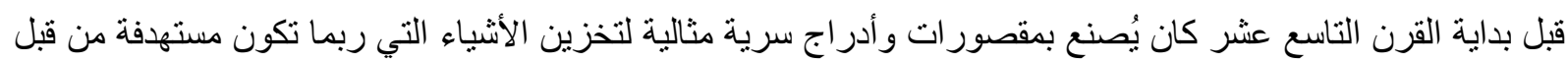

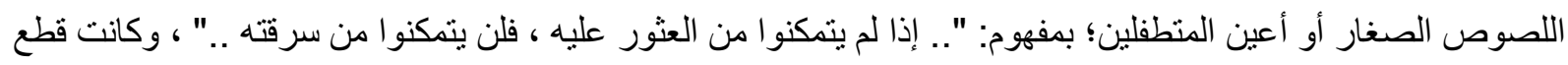

الأثاث هذه نثير إلى ثروة صاحب المنزل (؛).
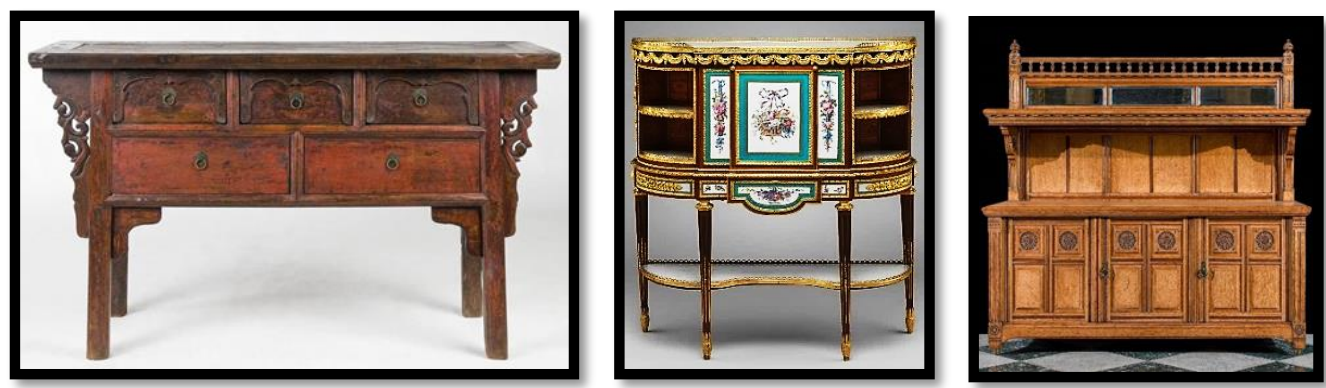

شكل (ץ): بصض مقصورات الأثاث السرية Secret compartments الثائعة في العصر الفيكتوري (؛) 
يلجأ المصممون إلى ابتكار بعض الحيل التصميمية لإخفاء بعض المساحات الداخلية ؛ حيث فرضت علينا التحديات الحياتية التخلى عن المفاهيم التقليدية للتصميم الداخلى والإهتمام براحة الإنسان وتأمينه داخل الفراغ الداخلى ؛ وذللك من خلال صياغة تصميمية تغير الوجهة الذهنية التى ينظر إليها لحل المشكلات فى منظومة مبتكرة، وتتقلنا إلى حالة غنية يتلاقى

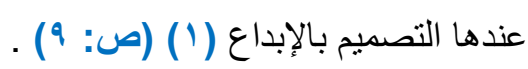
و هناك العديد من الأسباب التى يلجأ إليها المصممون لتصميم تلكا المساحات ودمجها وإخفائها داخل التصميم بثكل مبتكر..

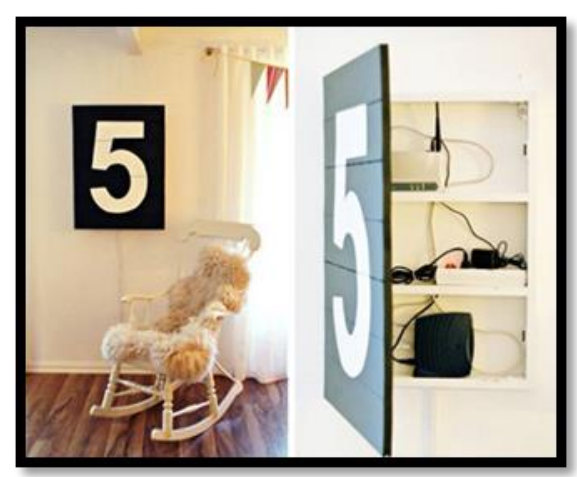

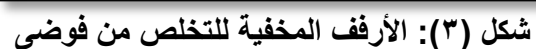
الأسلاك والتوصيلات بثكل جمالى فى التصميم الداخلى

ومنها:

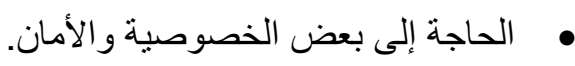

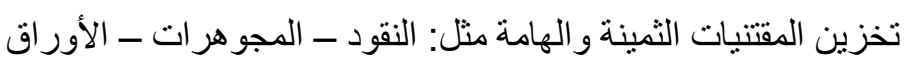
و المستندات الهامة ــ أدوات تكنولوجيا المعلومات ـ مستلزمات الطوارئ ـ التذكار ات و الصور ... و غيرها، بعيداً عن شراء خزائن حديدية غالية الثمن، وتكون عرضة للسرقة لأنها مستهدفة. • التأثير البصرى الجيد وتوفير المظهر المثالى نتيجة إخفاء أماكن التخزين الخاصة بالمؤن والمقنيات والتخلص من فوضى الكابلات و الأسلاك و التوصيلات غير ها ، كما انها أحياناً تقدم حلولاً لمشكلات وضن ولات بصرية تؤذى العين. إخفاء بعض عيوب التصميم الداخلى. حماية الأطفال من العبث بالمو اد الخطرة.

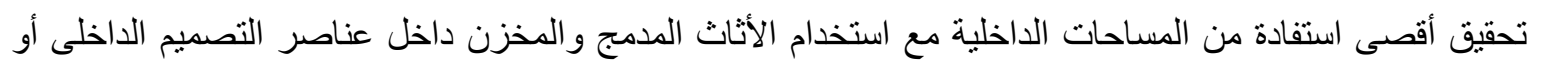
الإستفادة من الفر اغات المهملة ودمجها فى التصميم و استغلالها بطريقة متلى. للتأمل و الهدوء و إعادة نرتيب الأفكار وشحن الطاقة خاصة للمبدعين و الكتاب. إضفاء روح المغامرة والمتعة عند افتناء أحد الغرف السرية أو الأثاث المخفى، أو تصميمها كغرف للعب الأطفال مثل ولث القصص الخيالية المحببة لديهر.

\section{r- الأبعاد النفسية والقلسفية للأثاث والغزف السرية:} تتضمن عملية تثكيل الفراغ الداخلى للمساحات العديد من العلاقات المنداخلة؛ فيدخل المضمون الإنتفاعى (الوظيفى) فى ولى نطاق إبداع الثق المادى الذى يهدف إلى تحقيق الكفاءة و الر احة الفسيولوجية و الإجتماعية والأمن و الأمان لقاطنى المكان(ب). وتوافر المساحات السرية داخل الفراغ يضفي أبعاداً منها ما يلى:

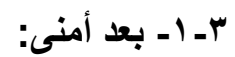
• تأمين الأفراد و المقتنيات الثمينة أو الثخصية. • حماية الأطفال وسلامتهم من المواد الغير آمنة و المعدات الخطرة.

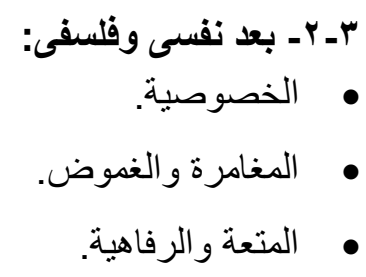


دمجها داخل التصميم يضفى الإستمر ارية و الإنغلاق.

فالمسألة تتعلق بر احة الفرد وتأمينه و اختيار سبل الرفاهية وخلق أجو اء تنتشل الإنسان من دو ائر الإرهاق اليومى وتحدد

$$
\text { أفكاره وتمده بحيوية نفسية تعينه على تجاوز المعوقات بـ ل... }
$$

عـ الأساليب التصميمية:

تفنن الكثير من المصممين فى ابتكار العديد من الطرق الإبداعية لتصميم واخفاء الغرف والأدر اج السرية؛ حيث ترتفع قيمة

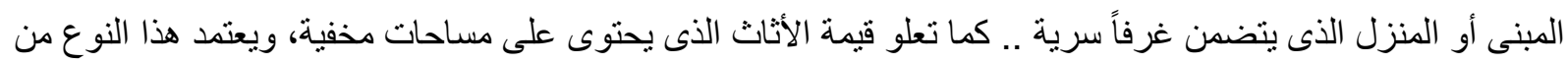
التصميمات على التفكير الإبداعى و التخطيط الدقيق وقدرة المصمم وتفرده فى الإبداع ووضع التصور ات و الحلول للوصول

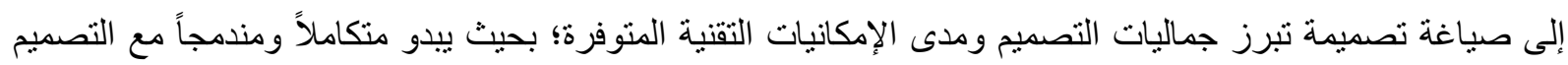
الداخلى للفر اغ.

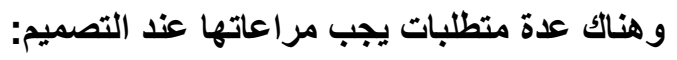
• اختيار الموقع المناسب: اختيار الزاوية بعناية.

• التمويه: تصميم الكيفية التى سيكون عليها الإخفاء بناءً على التقنية المر اد الحصول عليها. • اختيار الوسيلة المساعدة:

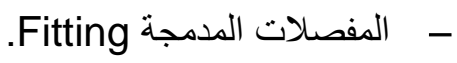
_ الوسائل التكنولوجية Technology: التحكم عن بعد (ريموت كنترول) ـ الكارت الذكى ـ الأقفال الإكترونية ـ التكنولوجيا التفاعلية (كالمجسات Sensors).
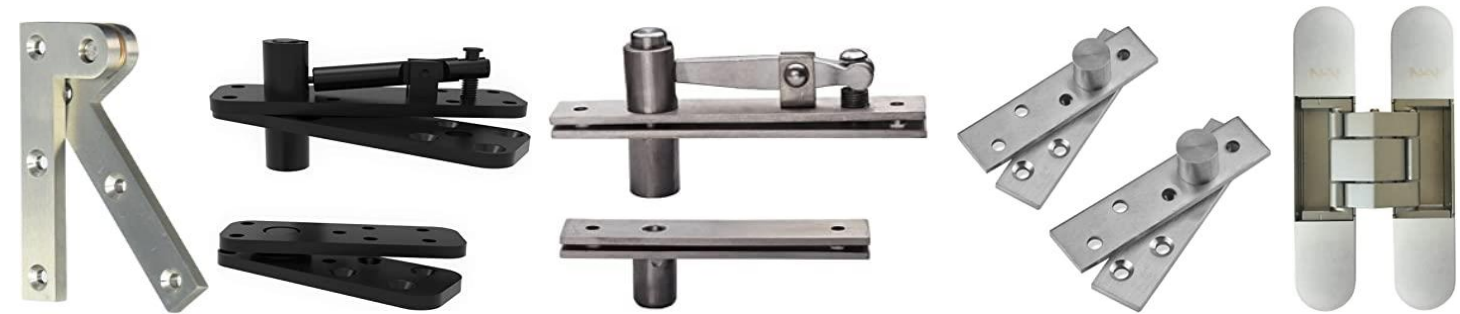

شكل (؛): بعض أثكال المفصلات غير المرئية Invisible Hinge (من موقع شركة أمازون amazon)
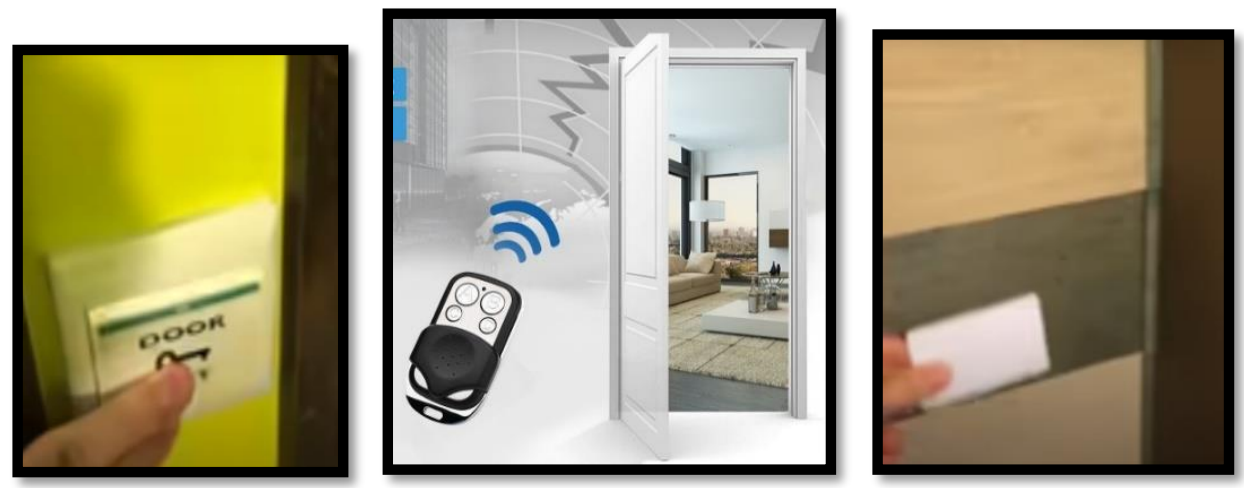

شكل (0): بعض الوسائل المساعدة المستخمة فى الأثاث والغرف السرية كالمفصلات الغير مرئية Invisible Hinge - الكارت الأكى ـ

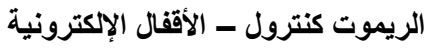




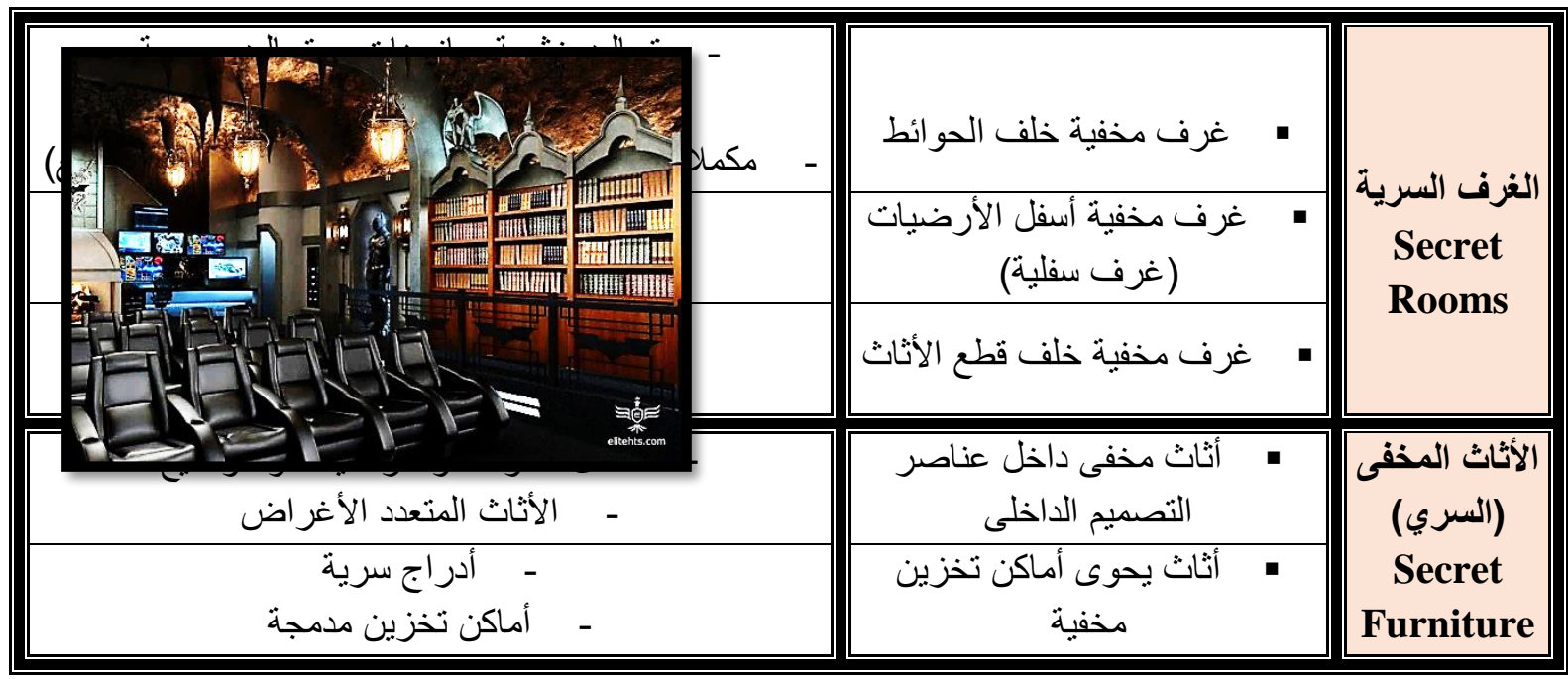

\section{مخطط توضيحى (1): الأثاث والغرف السرية}

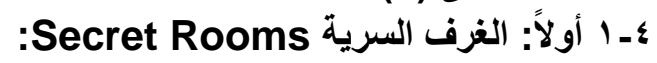

عندما نتحدث عن الغرف السرية فإننا نتحدث عن أبواب تندمج داخل التصميم الداخلى بحيث لا يتم اكتشافها إلا من قبل أولئك الذين يعوفون ذلك ، و غالباً ما تستخدم لإخفاء غرفة الملابس Dressing room أو غرفة التخزين Storage أو المكتب الثخصى personal office أو غرف السينما المنزلية home cinema .. و وغير ها؛ حيث يتم تصميمها من الداخل حسب الحاجة والغرض المراد منها. وفيما يلى بعض الطرق الإبتكارية المتعددة لإخفاء وتمويه تلكل

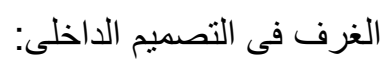

شكل (†): غرفة السينما المنزلية The secret Home Cinema

ــ 1 - أبر غرف مخفية خلف الحوائط: يتم تمويه باب تلك الغرف ليبدو جزءواً من التصميم الداخلى أو كعنصر معماري مع استخدام المفصلات الغير مرئية ومزلاج باب بسيط لتأمينه (مغلاق) ، وتعتبر تجاليد الحو ائط وبعض مكملات التصميم الداخلى كالتابلو هات و المر آه والموقد هى اختبارات متنو عة بله

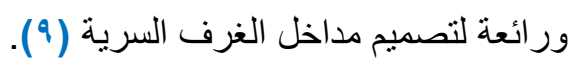
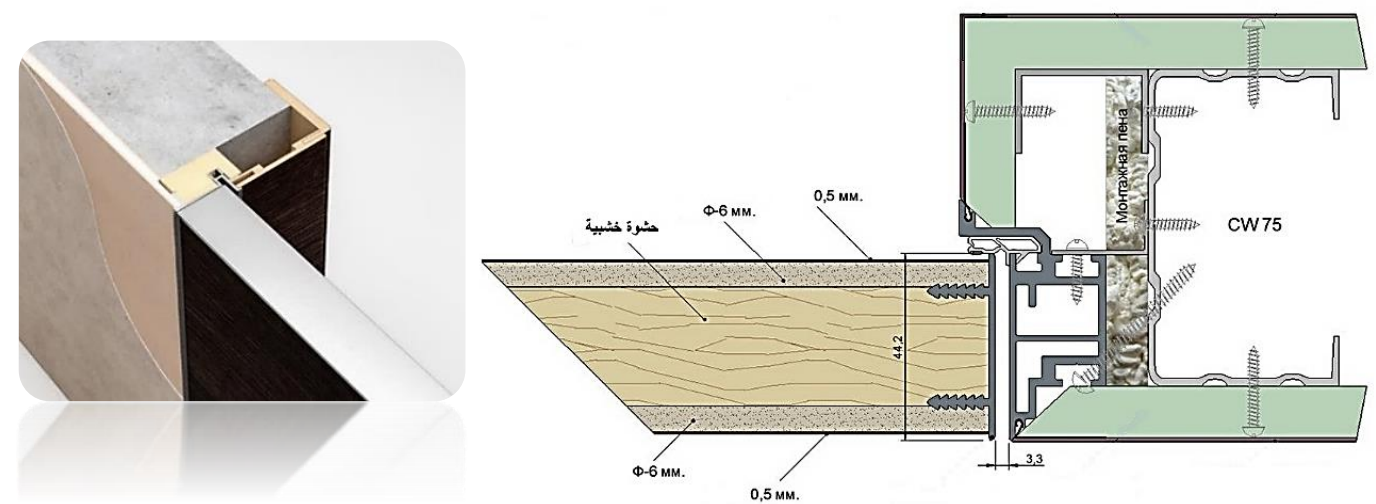

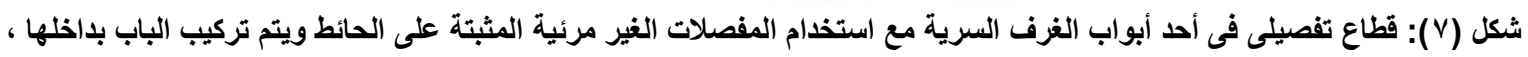

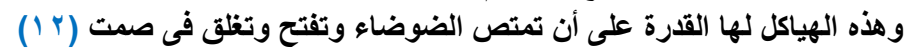




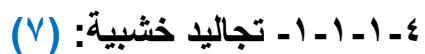

تتيح التجاليد الخشبية فى الحوائط تصميمات مبتكرة يمكن من خلالها تمويه و إخفاء مداخل الغرف السرية ، وذلك من خلال عمل تشكيلات هندسية ومديولية فى التصميم طبقاً لمقاسات الباب ومكان إخفاءه، و أيضاً حسب شكل ونوع عل الخشب المستخدم فى التجليد، وكثير اً ما تستخدم فى إخفاء غرف الملابس أو غرف التخزين التى تساعد فى الحفاظ على المكان ومنع الفوضى.
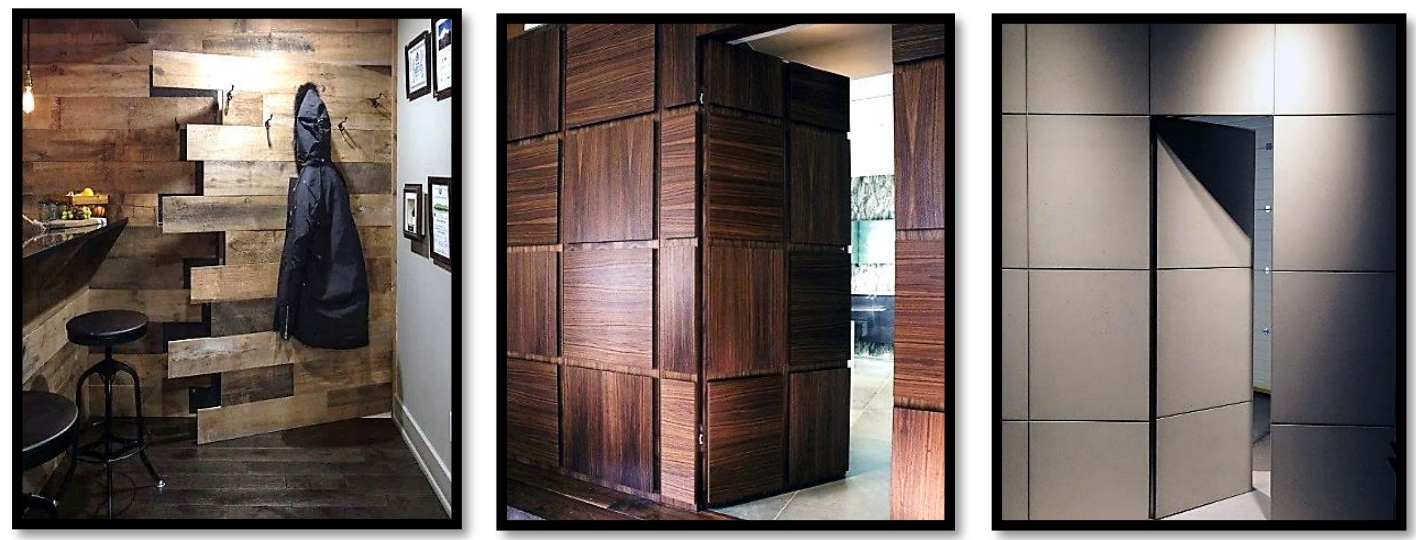

شكل (^): استخام تجاليد الحوائط الحوائط الخثبية فى دمج وإخفاء مداخل الغرف السرية فى التصميم الداخلى
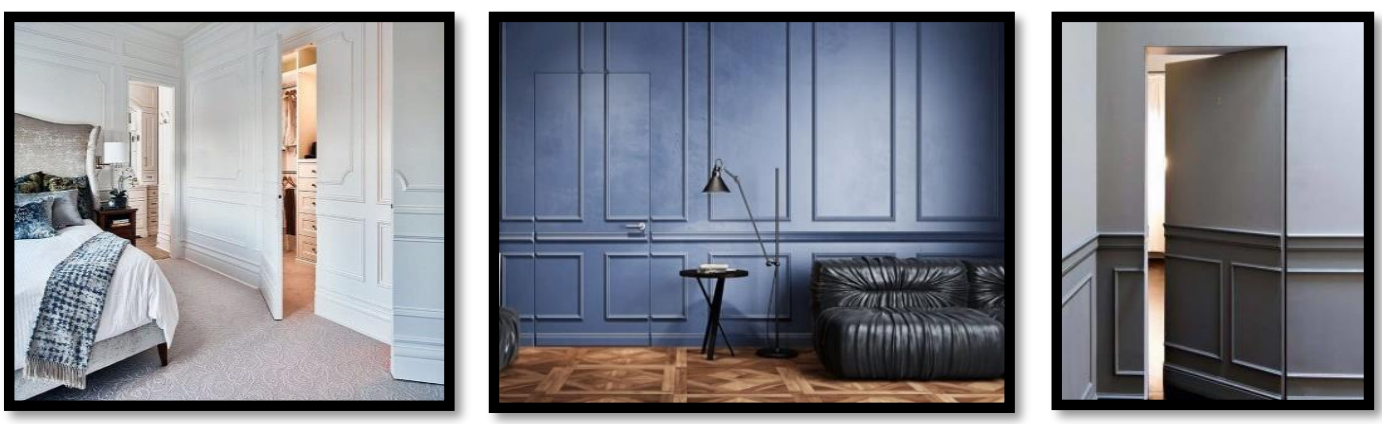

شكل (9): استخام البانوهات الخثبية فى اخفاء بعض المساحات الاخلية يضفى شعوراً بالإستمرارية وتكامل التصميم

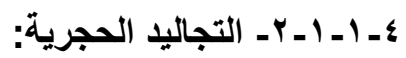

التجاليد الحجرية هى إحدى الطرق المستخدمة أيضاً فى إخفاء وتمويه مداخل وأبو اب الغرف السرية؛ بحيث يراغى دمج الأحجار بشكل غير ملحوظ داخل التصميم الداخلى. و عادة ما تكون ضلفة الباب تكون بسمك هـ سم أما هذا النوع من وند

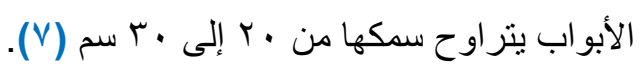
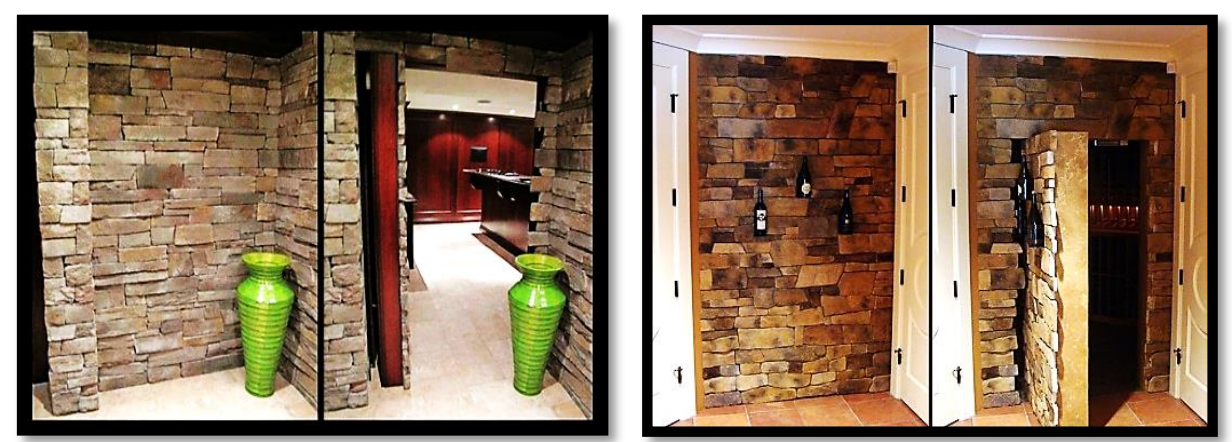

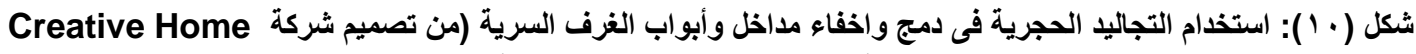
( Engineering 


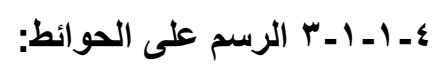

يلعب الدور الزخرفى دوراً أيضاً فى الإخفاء. فيمكن عمل رسم زخرفى على الحائط المؤدى للغرفة السرية أو تثيبت ورق

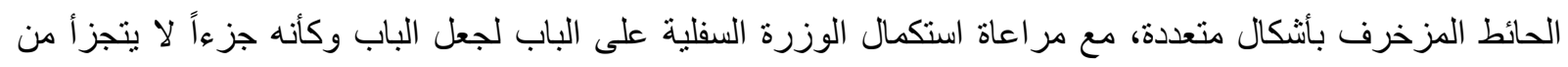
التصميم الداخلى بالحائط ويكون مخفى تماماً فى حالة الغلق.
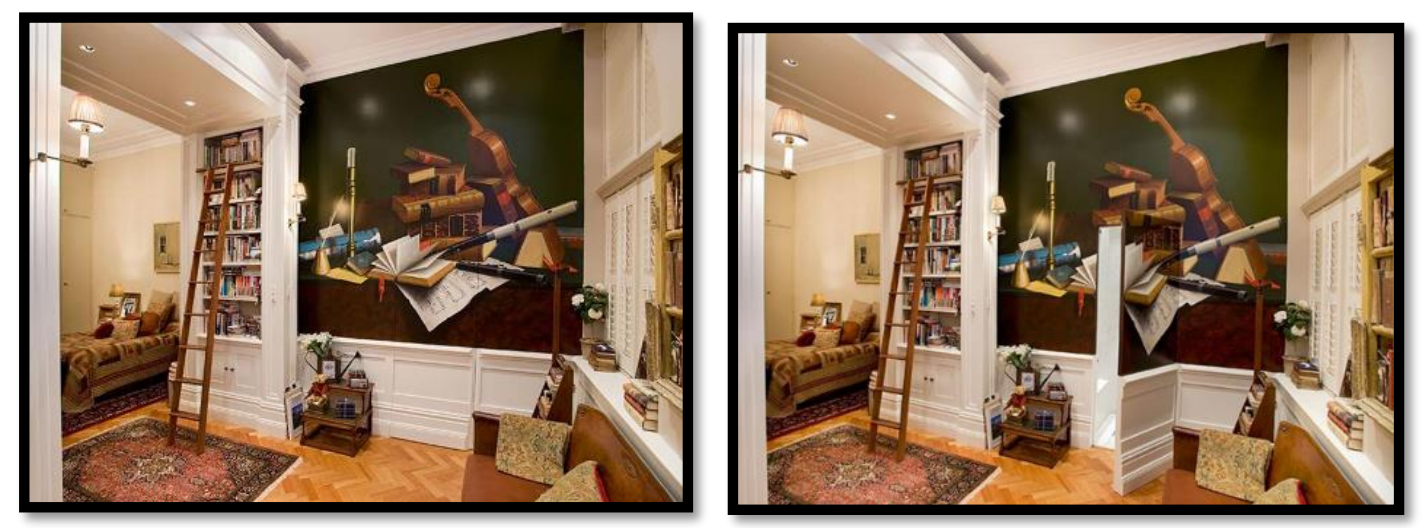

شكل (1'): يوجد في هذه الصورة باب شبه غير مرئي يؤدي إلى حمام سري (من تصميم شركة Groth \& Sons هي شركة أسترالية اللتصميم الاخلي متخصصة فى الغرف السرية الفاخرة - سياني - استر اليا) (10)
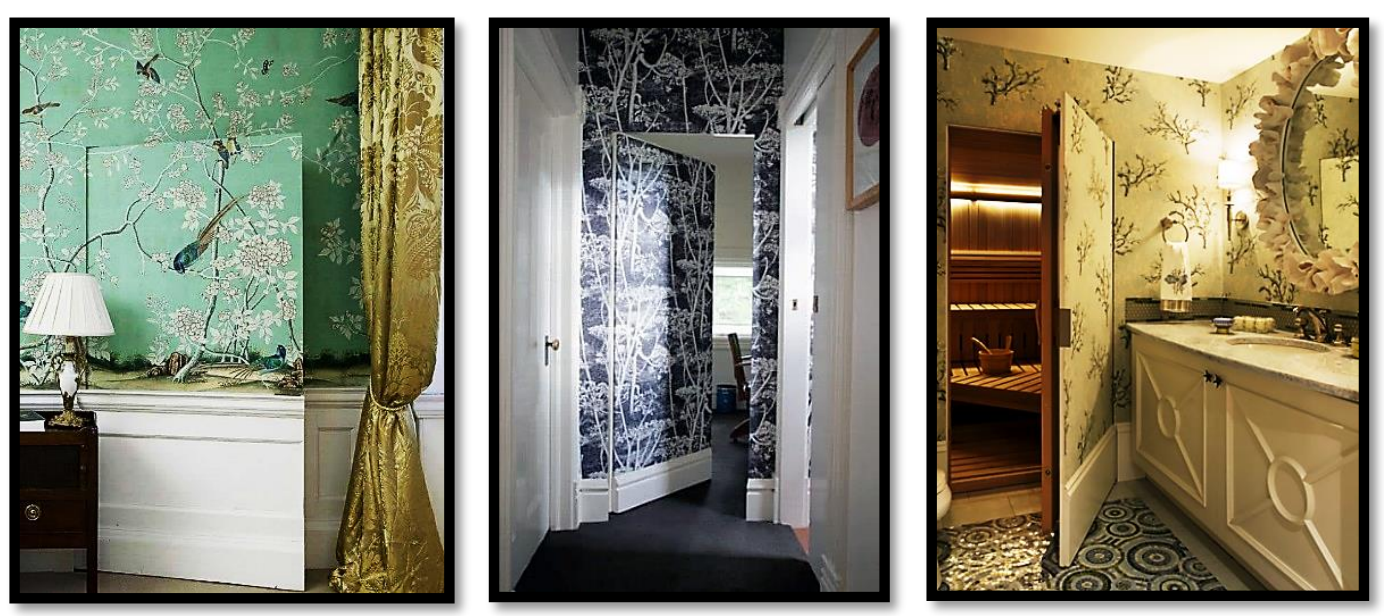

شكل (r l ): استخدام ورق الحائط المزخرف فى الغرف السرية (V)
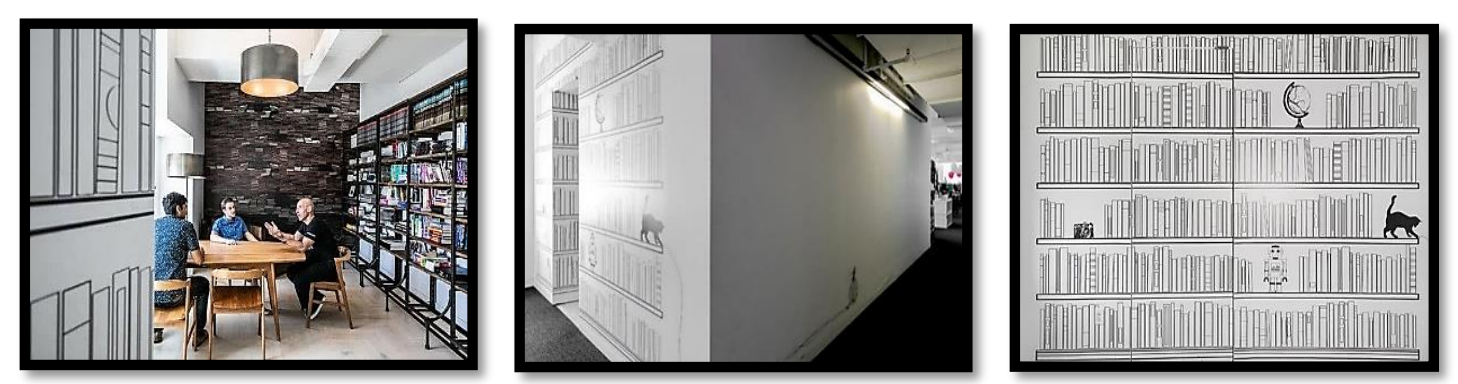

شكل (r ا): المكتبة السرية الهادئة The secret quiet library بالمقر الرئيسي لثركة Shutterstock ، في مبنى

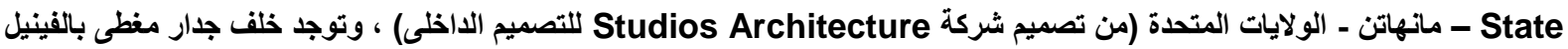
المطبوع عليه صورة لأرفف مليئة بالكتب ، لتكون غرفة الإسترخاء بالثركة لممارسة بعض الأنثطة مثل تنس الطاولة و اليوجا والإرضاع .. 


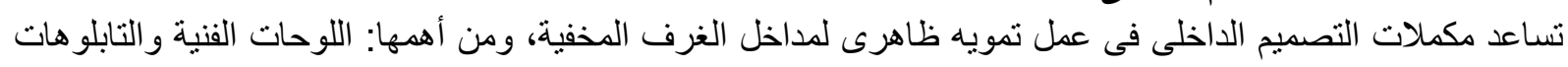
و المر آه و المدفأة و أيضاً السلالم الداخلية.

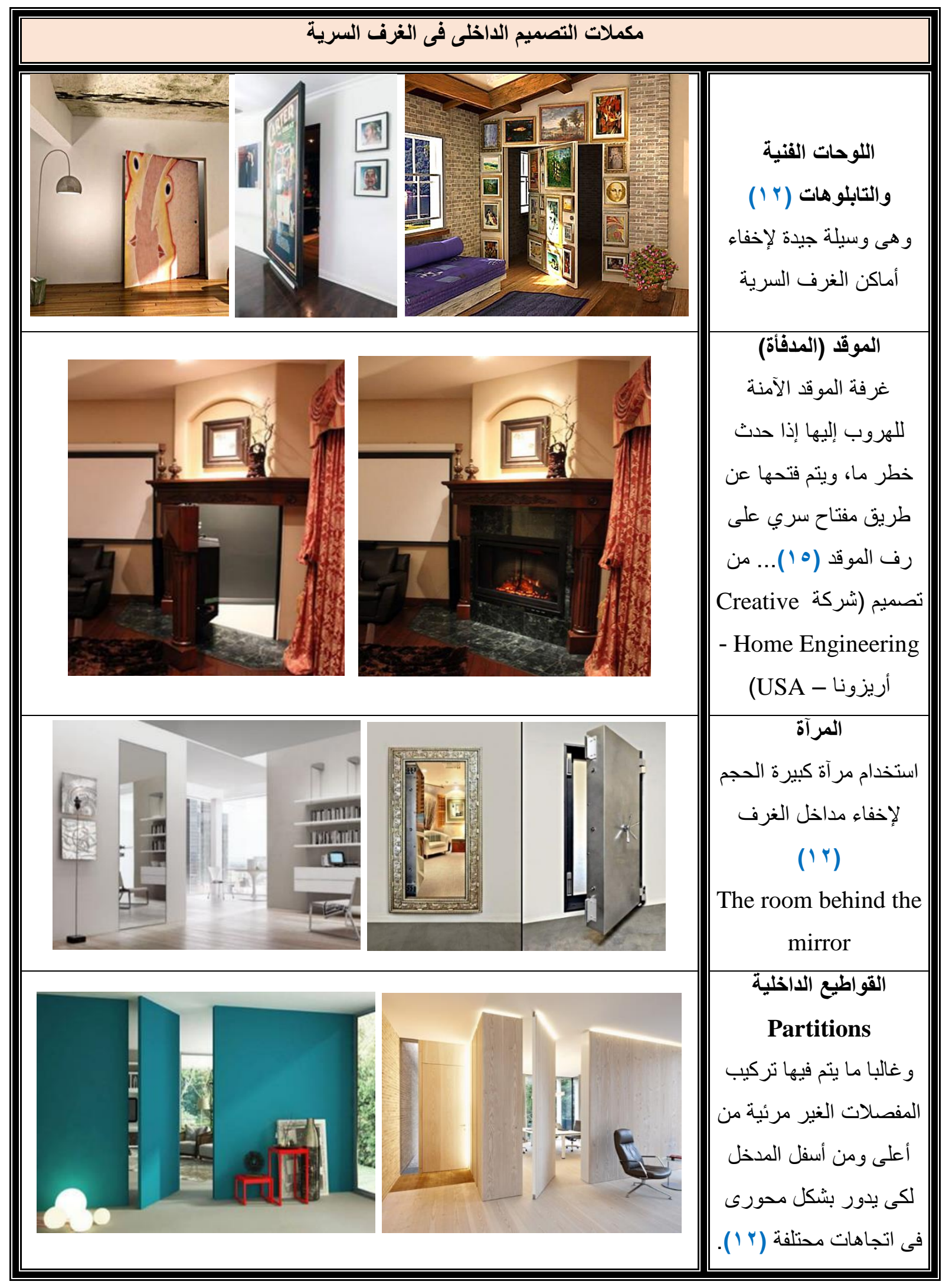




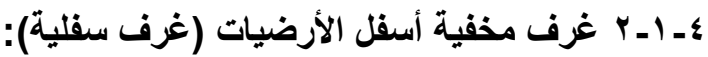
هناك القليل من التفاصيل المعمارية التى تمنح الفراغ الداخلى إحساساً بالغوض، والغيل الغرف اسفل الأرضيات إحدى هذه التفاصيل ؛ مع الحرص على تمويه الدذخل ودمجه فى التصميم الداخلى ليعطى بعد جمالى للمكان.

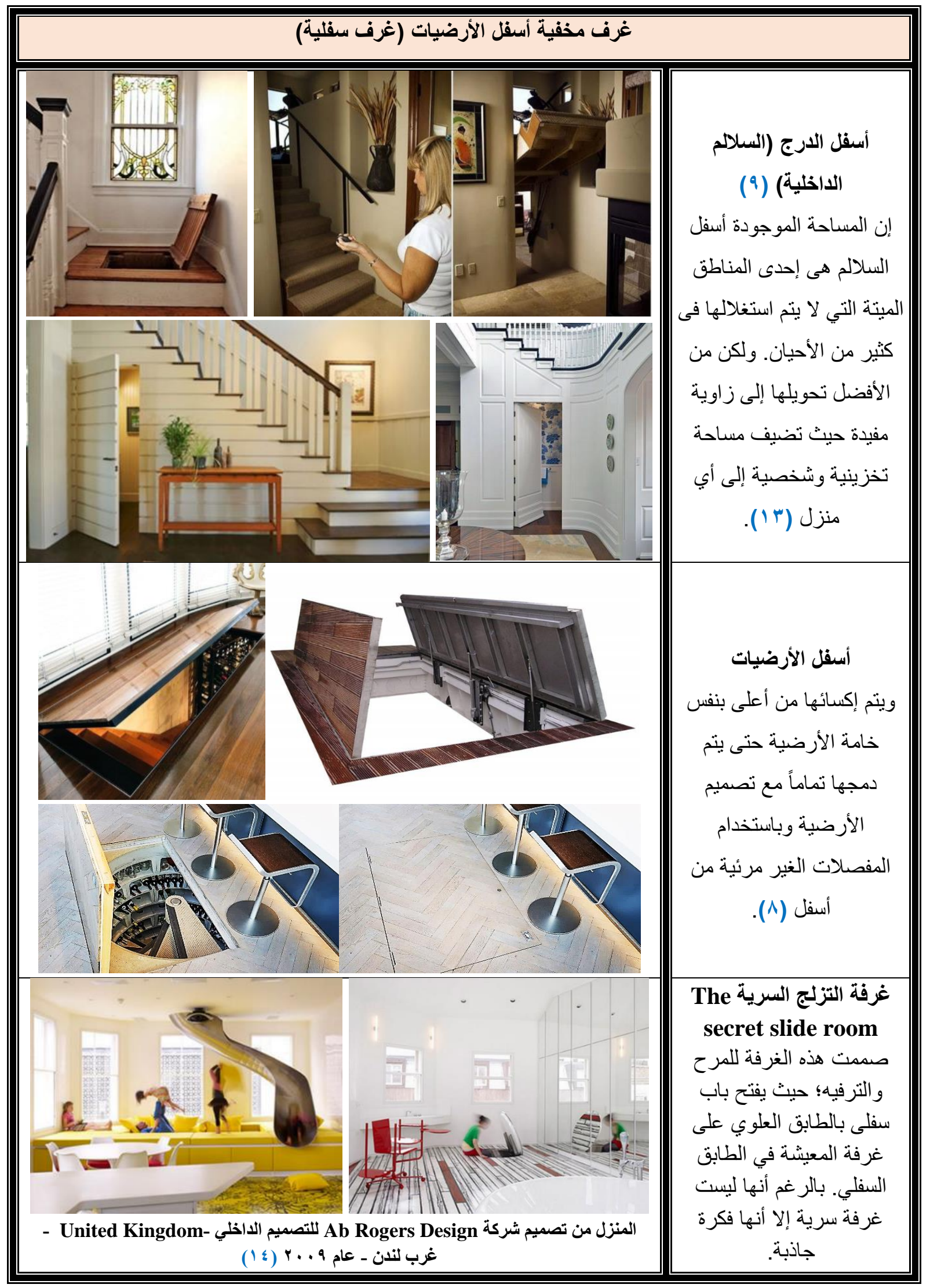




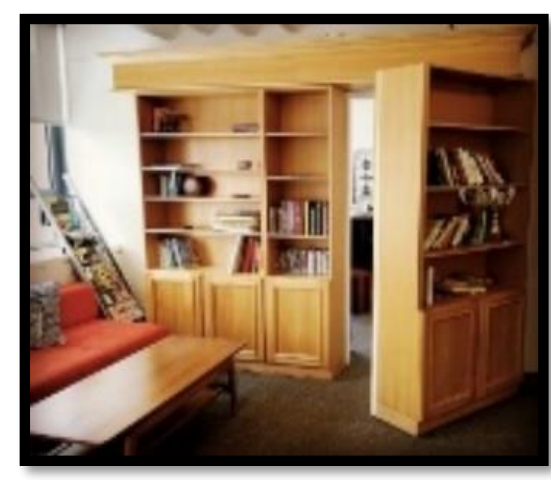

حينما تنواجد غرفة استراحة سرية خلف مكتبة الكتب أو أحد قطع الأثاث.. فإنها تضفي لمسة تصميمية مشوقة داخل المكان، مع استخدام المفصلات الغير مرئية ودمجها فى التصميم. و هذه الغرف لا توجد

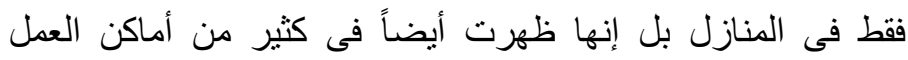

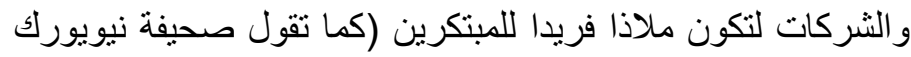

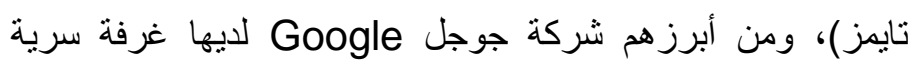

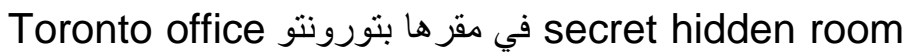
بكندا، ولا يمكن فتحها إلا عن طريق إمالة الكتاب الصحيح فى موضع الزر الخاص بقتح الغرفة (†).

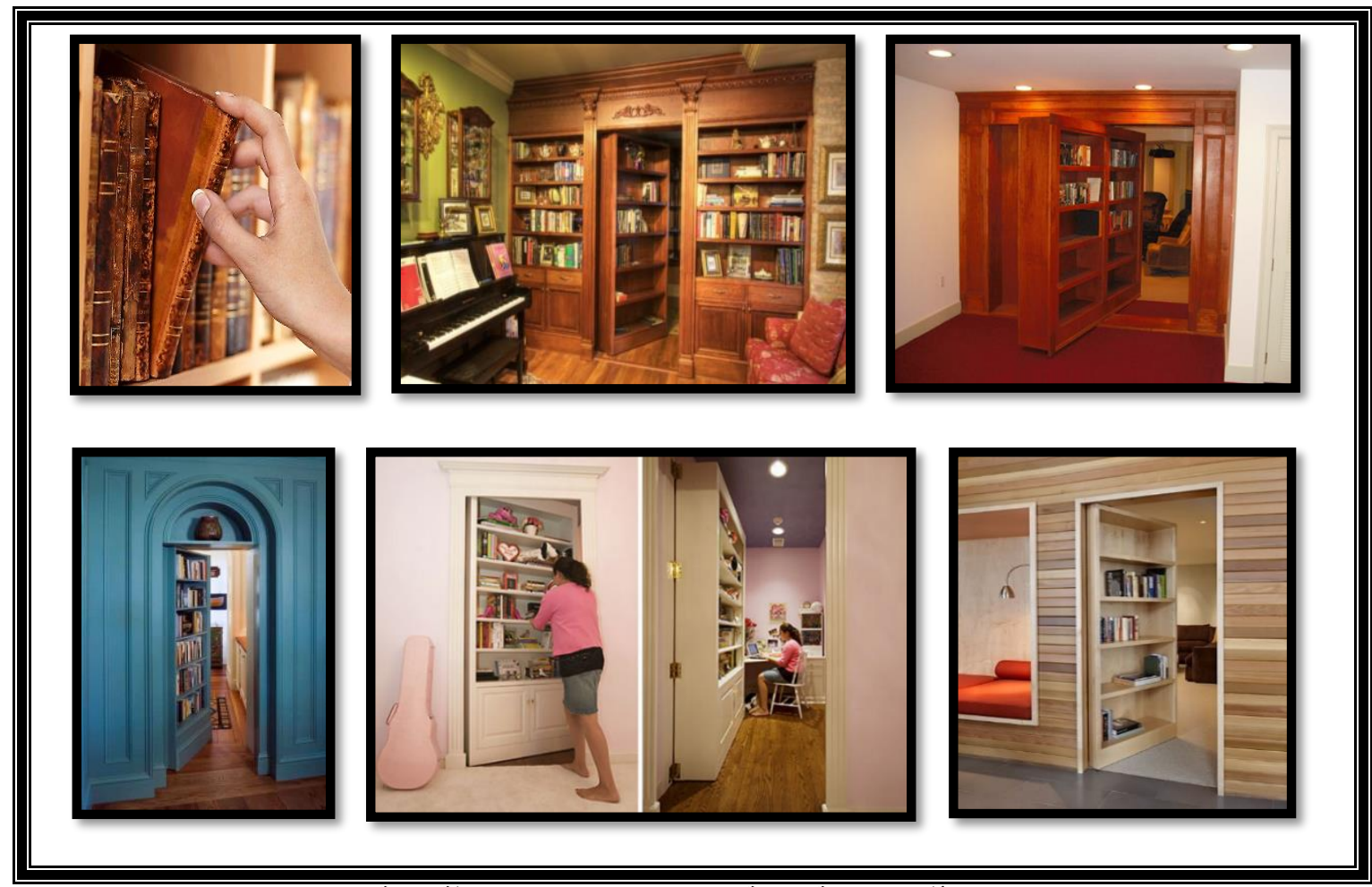

شكل (؛ (1): أفكار متنوعة لمكتبة الكتب النى تخفى ورائها غرفة سرية (V)

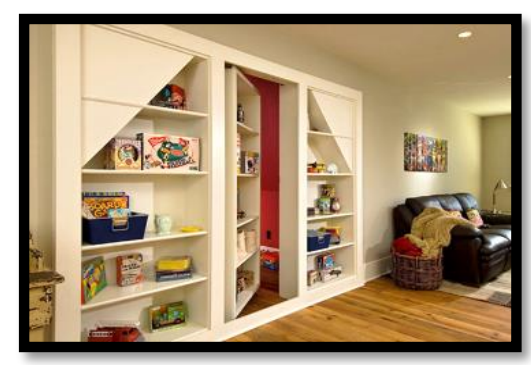

هذه الغرفة تسمى استوديو اليوجا السري The undercover yoga

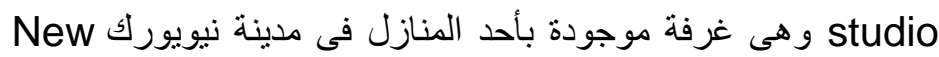
York

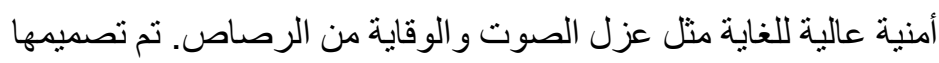

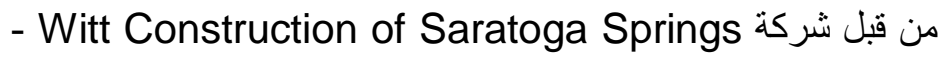
نيويورك، الولايات المتحدة (10). 
فبر اير r r r n مجلة التزاث والتصميم - المجلا الثاني - العدد السابع
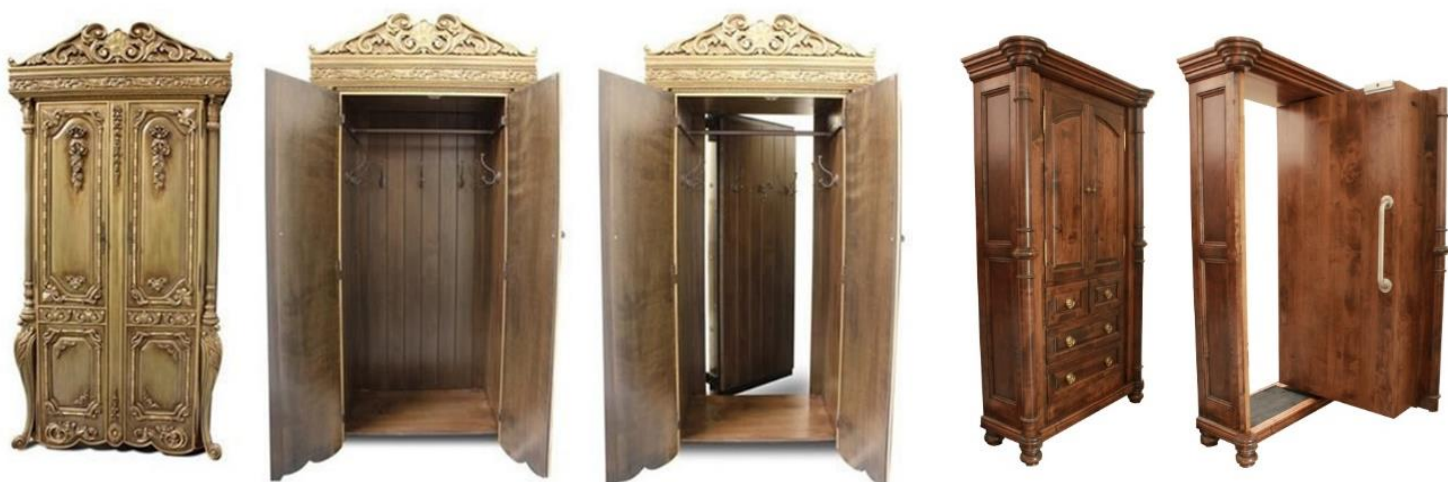

شكل (0 1 ): صور قد تبدو لقطعة أثاث عادية أو دو لاب للتخزين ولكنها فى الحقيقة تخفى مدخلاً لغرفة سرية (ب ا )
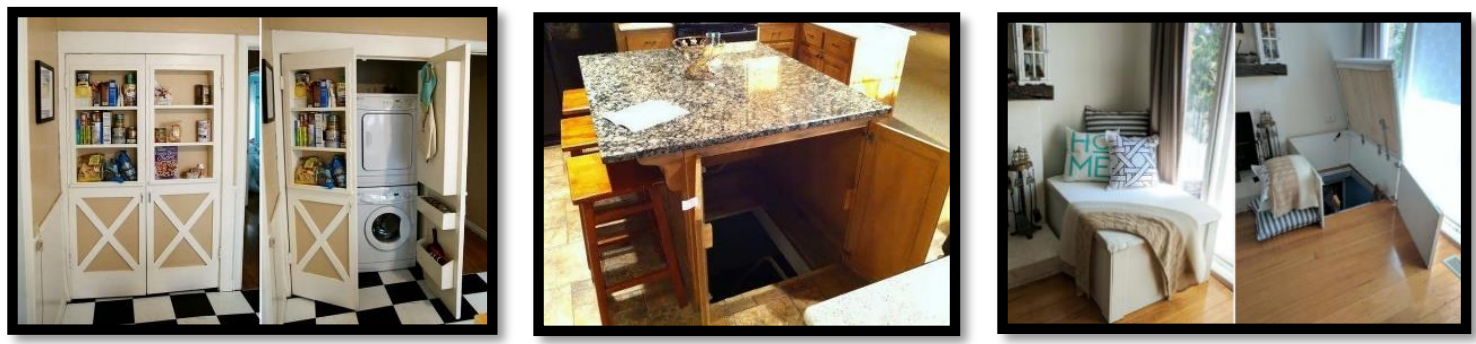

شكل (17 ) : صور لبعض قطع الأثاث التى تخفى غرفة للتخزين أو غرفة للغسيل للحفاظ على المنزل من الفوضى (ب ا )

من المتع حقاً وجود غرفة سرية فى المكان كما رأيناها فى الأفلام .. إنها إضافة معمارية ممتعة للمبانى والمنازل القديمة

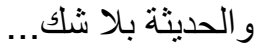

؛ - ؟- ثانياً: الأثاث المخفى (السري) Secret Furniture

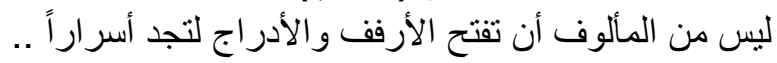

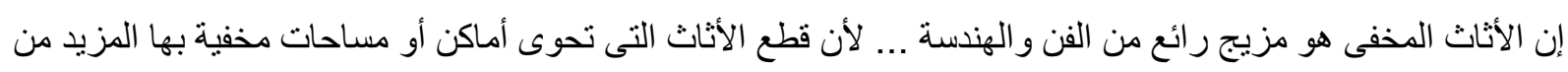

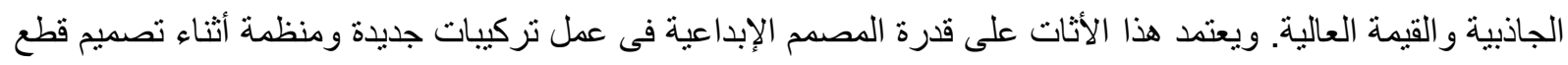

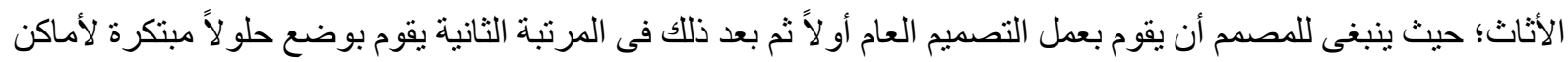
الأجزاء السرية داخل التصميم ... وستناول الأثاث المخفى داخل عناصر التصميم الداخلى و أيضاً الأثاث الذى يحوى أماكن تخزين مخفية فيما يلى:

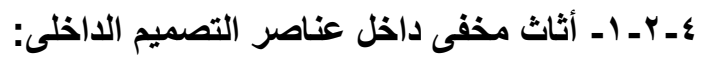
إن دمج الأثاث في عناصر التصميم الداخلى كالحو ائطو الأرضيات و الأسقف يقدم حلو لاً كبيرة للمساحات الضيقة بشكل أساسى كما أنه يعطى تأثثير بصرياً جاذباً ، و هو مثالى للحصول على مساحات جيدة داخل الغرف سواء للعب الأطفال أو لممارسة الرياضة أو للحصول على أكثر من وظيفة داخل الفر اغ.

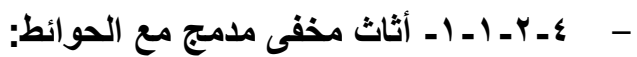
و هذا الأثاث شائع الإستخدام فى المساحات الضيقة والثقق السكنية الصغيرة ، ولكنه يعتمد بشكل أساسى على التقنيات و المفصلات التى توفر بدائل متعددة لدمج الأصاص داخل التصميم بالحائط. 


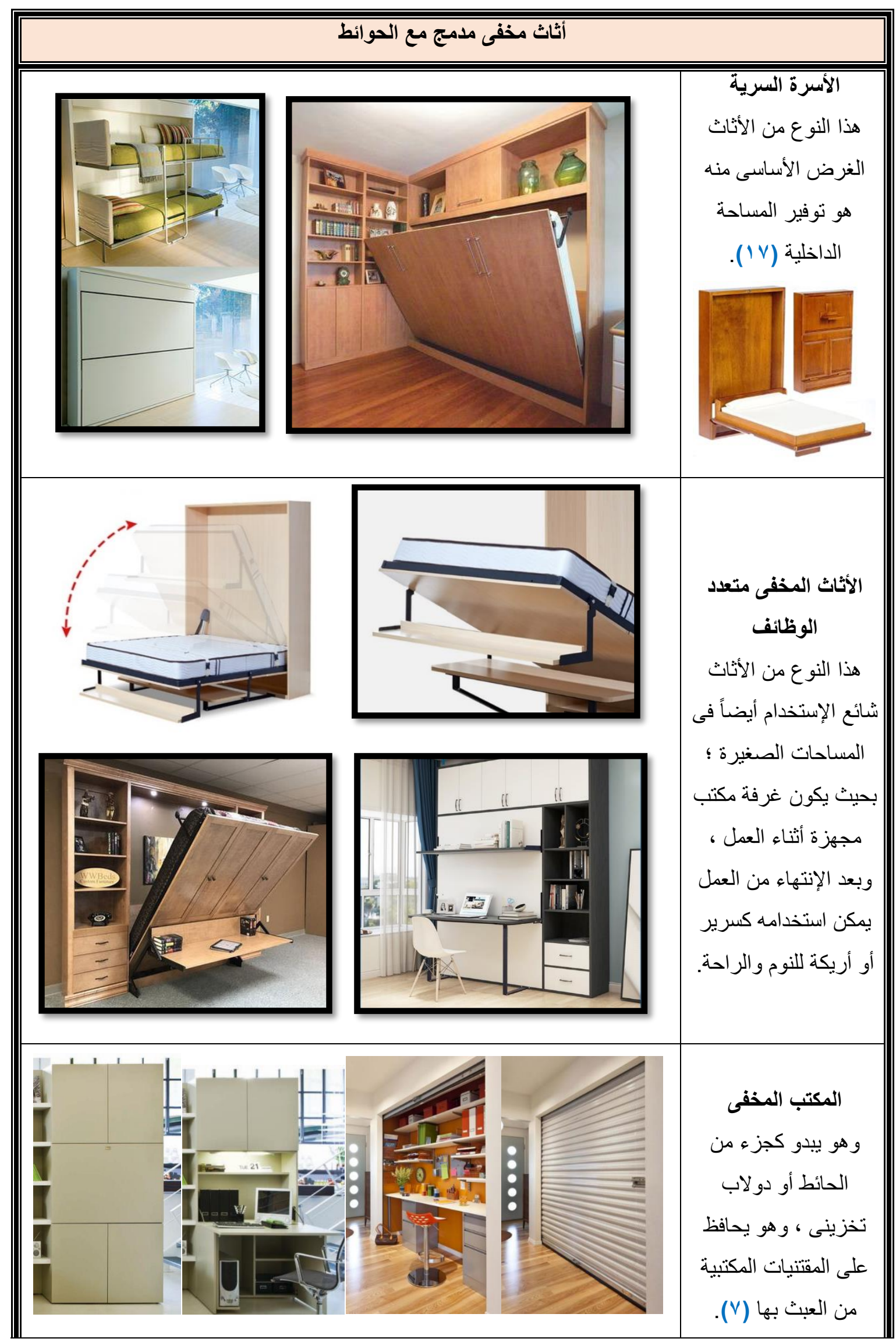




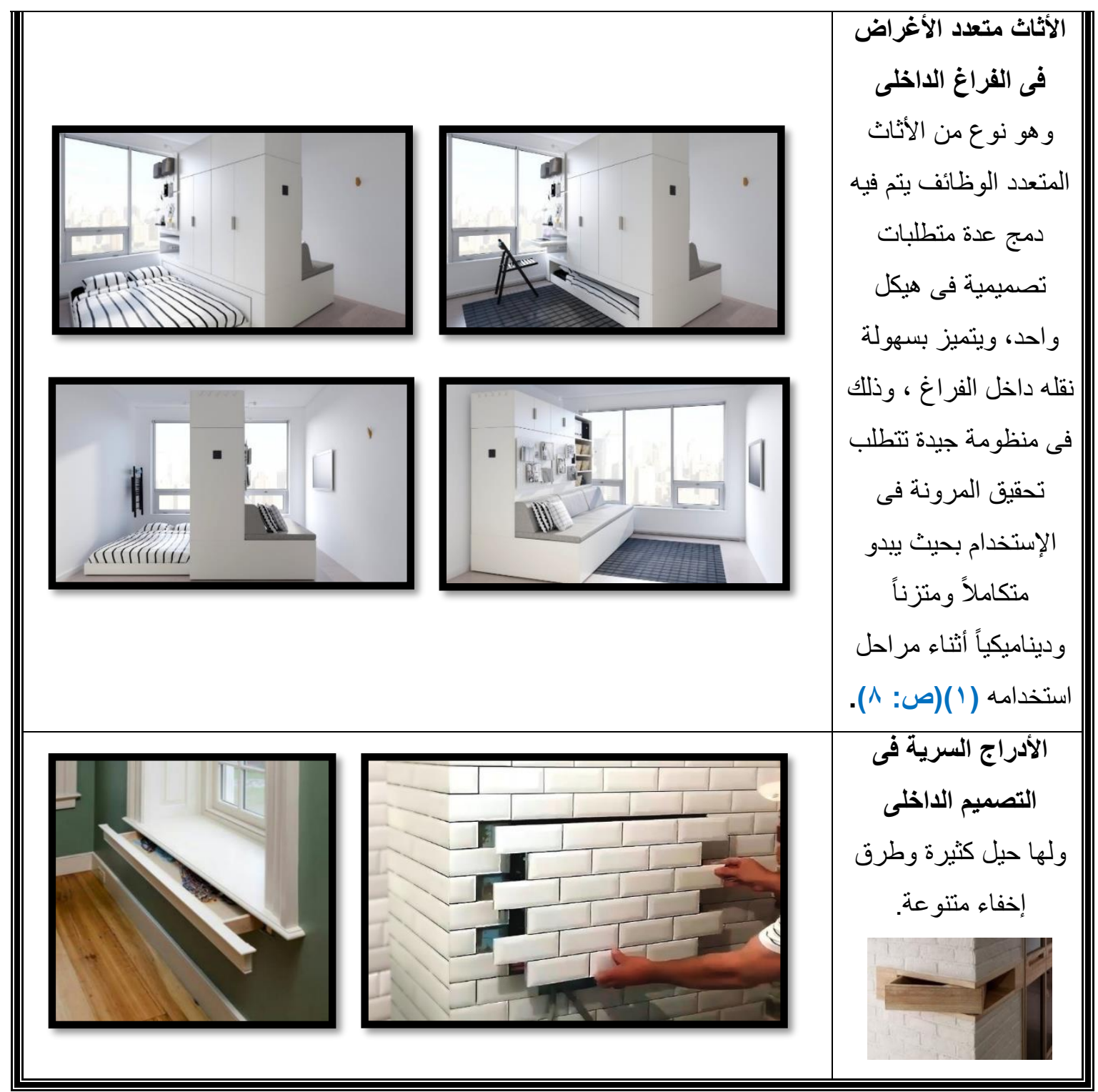

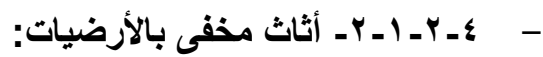

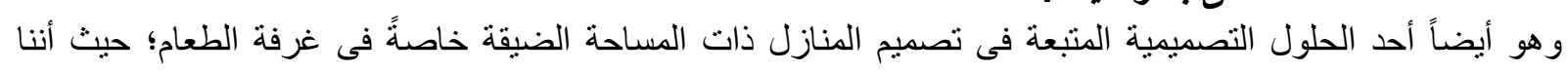
نستطيع استخدامها عند الحاجة فقط ومن ثم توفير مساحة جيدة بالمكان.
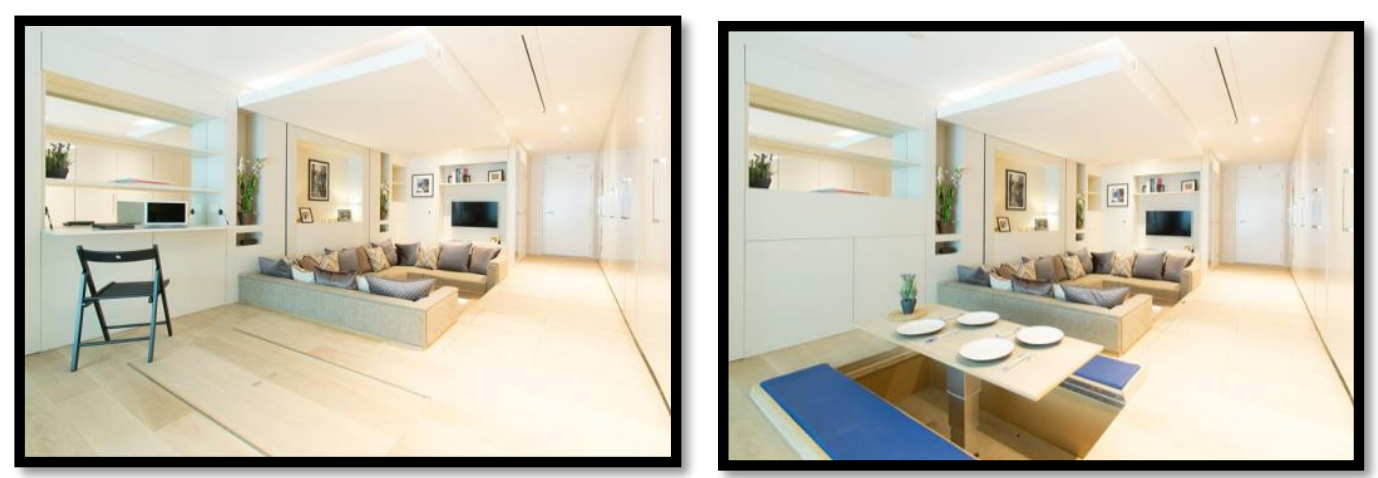

شكل (V V ): نموذج منضدة سفرة مخفية داخل الأرضية (9 ( ) 

يتم اللجوء إلى دمج أو تخزين الأثاث فى الأعلى عند السقف فئى حالة المساحات المحدودة للمنازل وحينما تتو افر الإمكانيات التقنية و التفصيلية لذلك ؛ حيث يجب مر اعاة التحميل الجيد وخفة وزن الخامات المستخدمة فى التصميم.
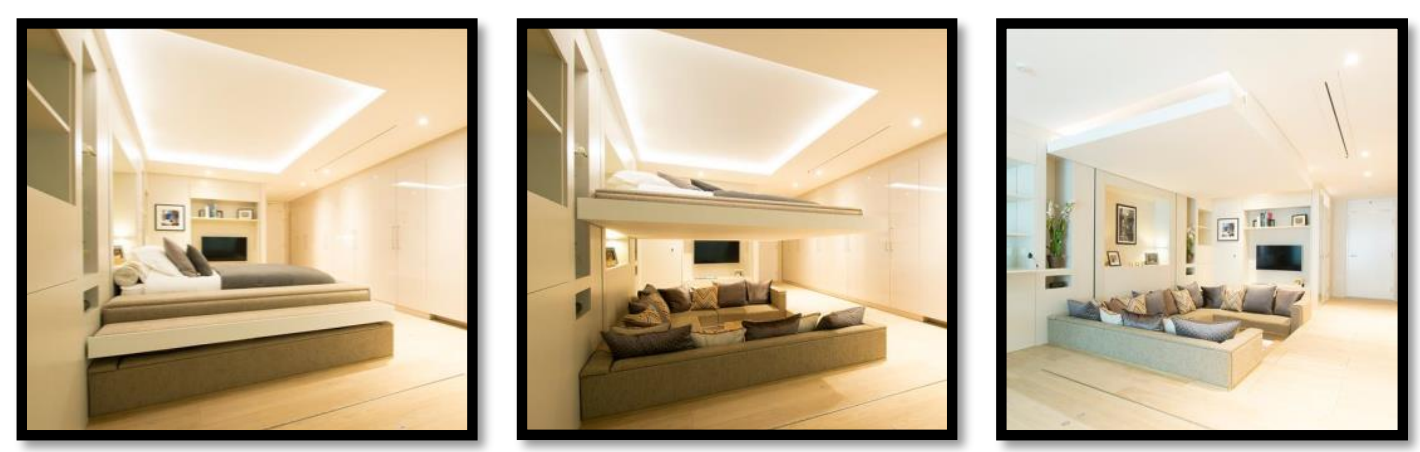

شكل (1) ): نموذج سرير مخبأ بالسقق (9 (1)

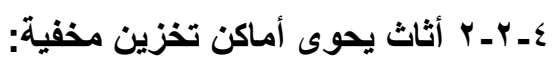

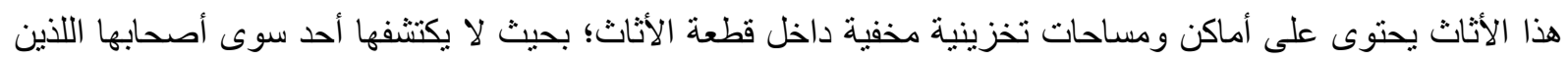
يعرفون مكانها جيداً. فعادةً ما توجد في أي قطعة أثاث "مساحات ميتة" حو الى بوصة أو اثنتين يتم استغلالها بذكاء، ويعتمد ذللك على مهارة المصمم وقدرته الإبداعية فى إيجاد حلول مبتكرة لإخفاء تلك المساحات داخل قطع الأثاث مع مر اعاة ألا توثر على التصميم العام لها. وفيما يلى بعض هذه الطرق الإبتكارية:

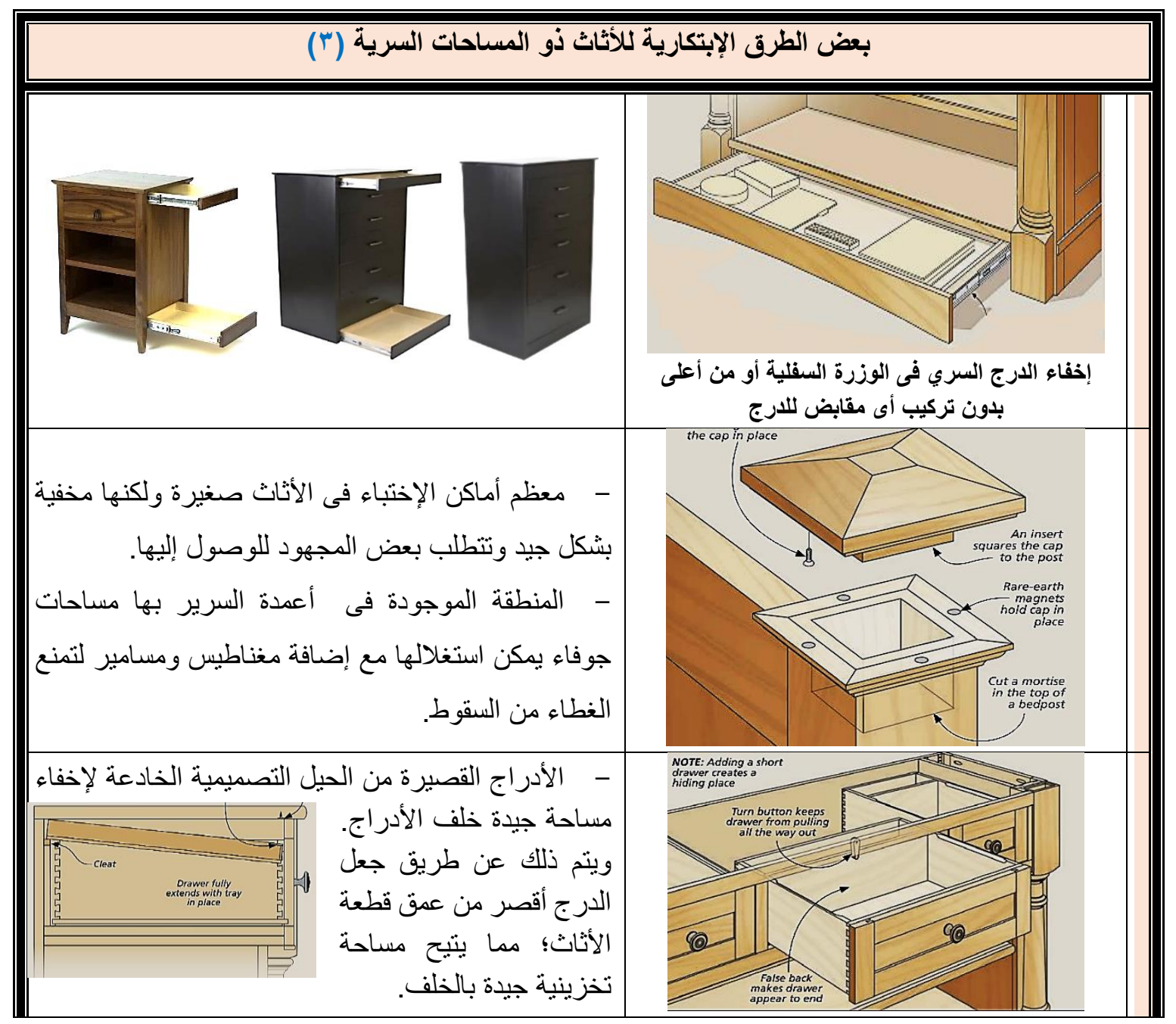




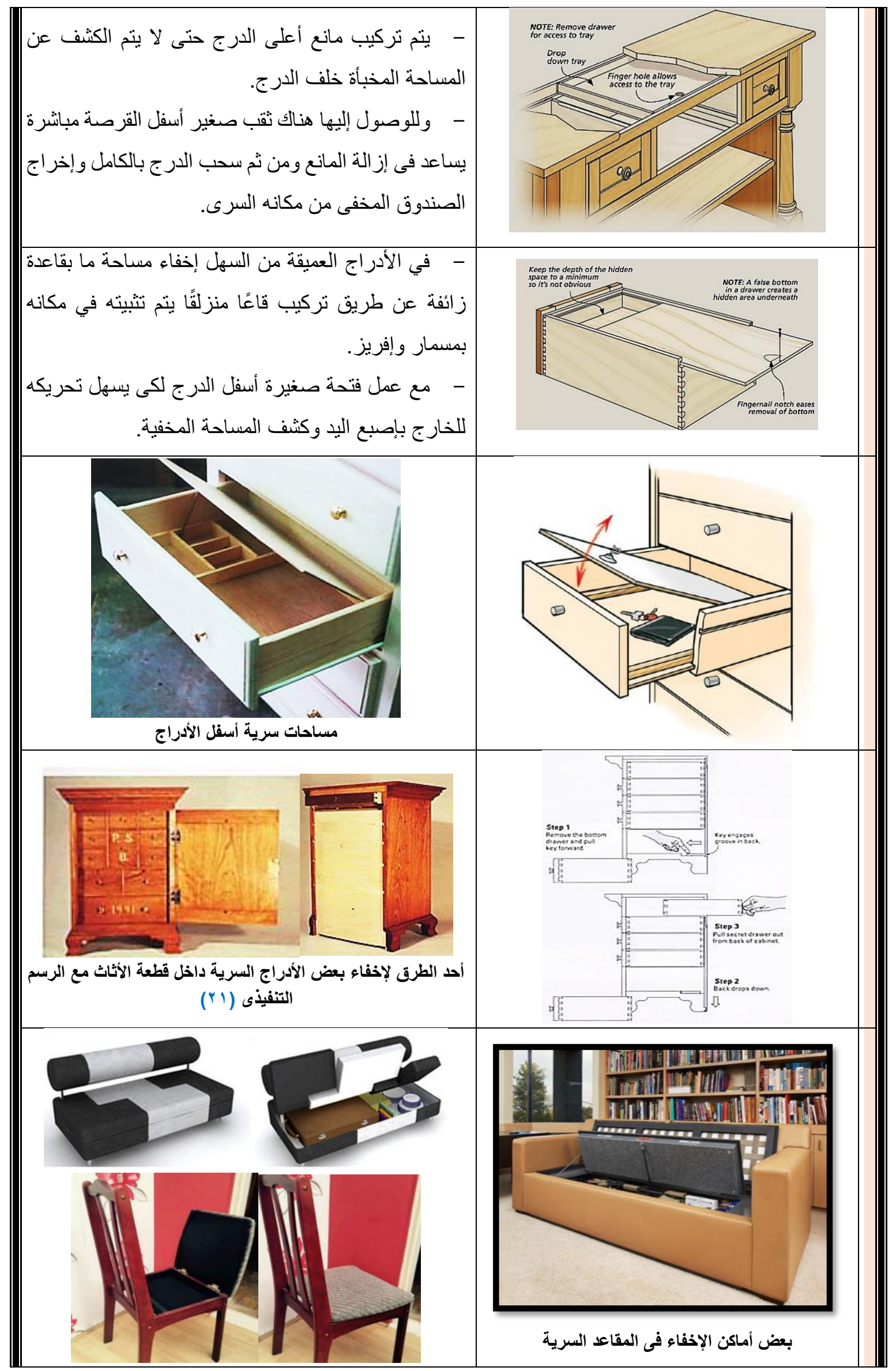




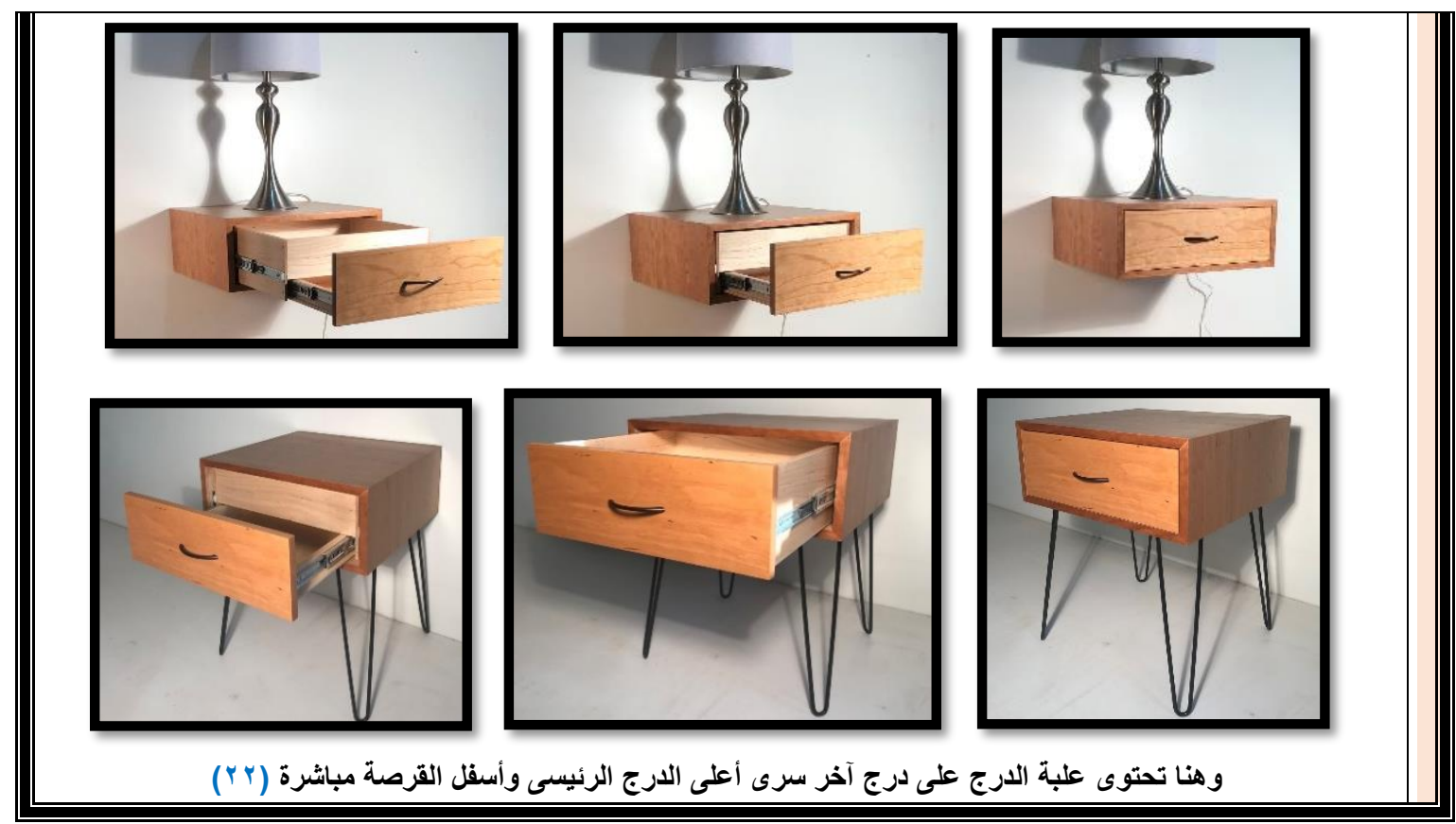

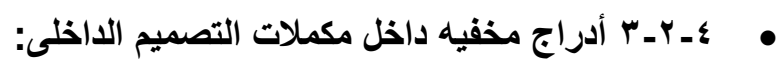
إن مكملات التصميم الداخلى لا غنى عنها داخل الفراغة، كما أنها تساعد كثبرا فى تكامل التصميم و الثكل العام للمكان، ويمكن استغلالها أيضاً بصورة جيدة لدمج أماكن سرية للإخفاء بها.

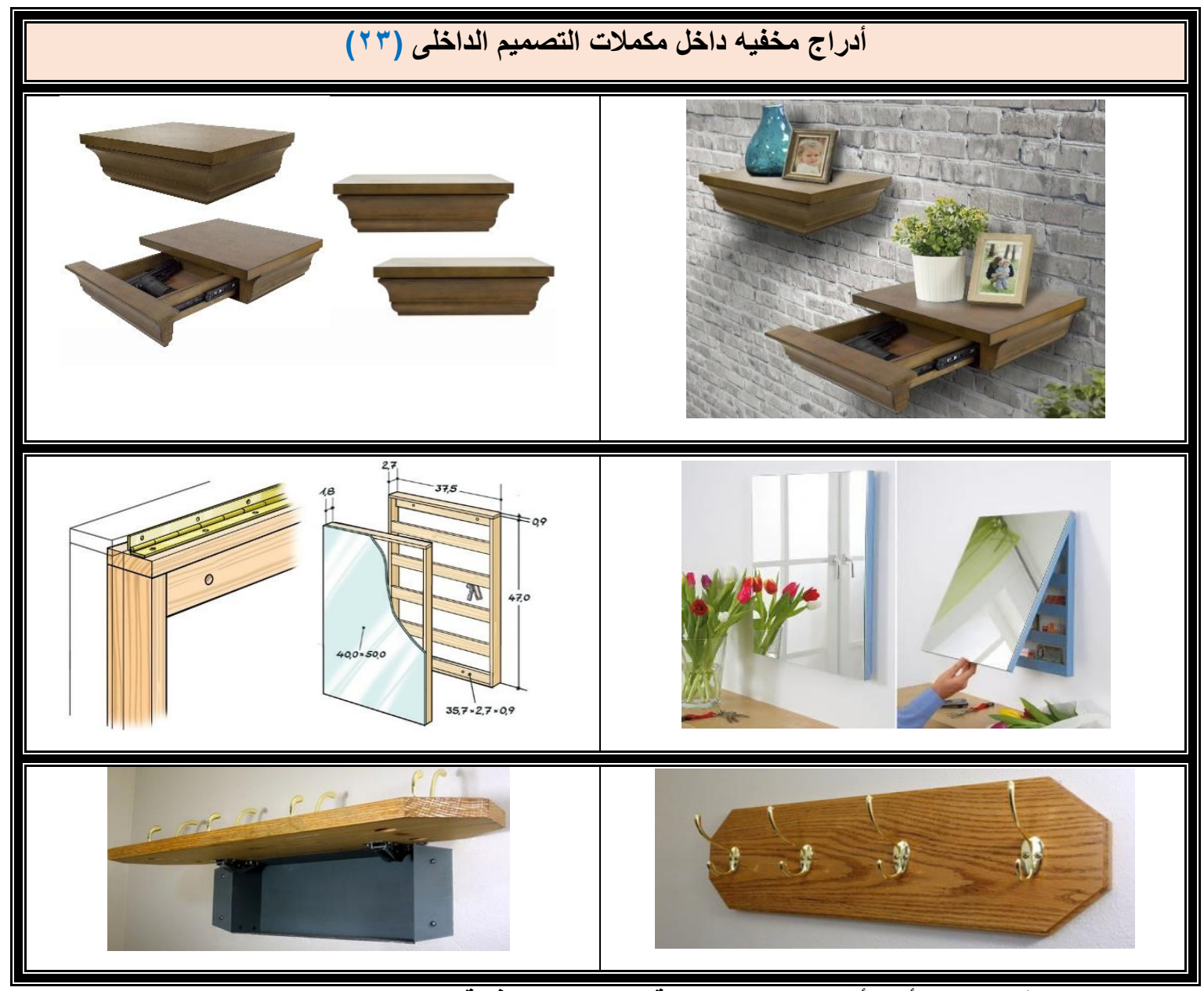

.... ومما سبق نستطيع القول بأن الأثاث والغرف السرية لها سحر وجاذبية لا يمكن انكاره .... 


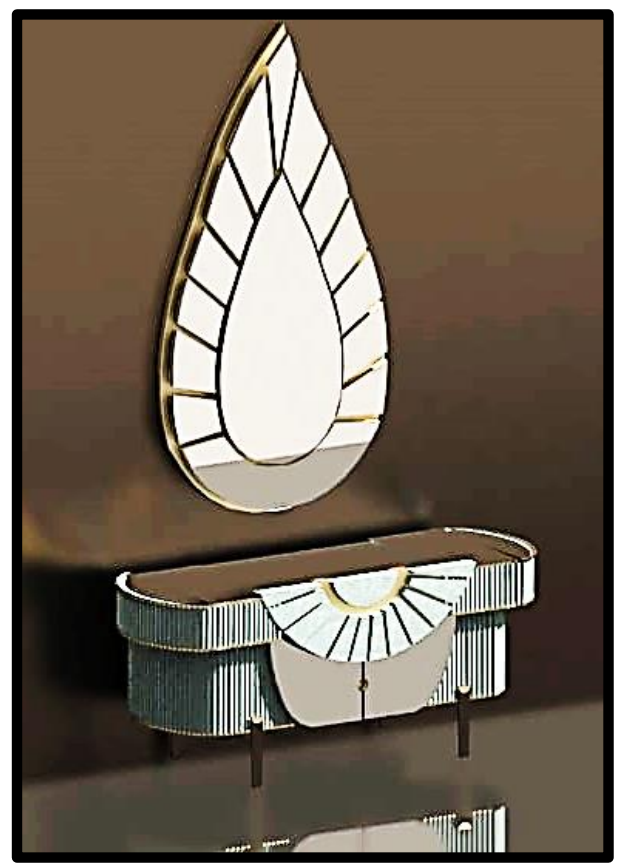

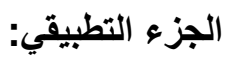

نم اختبار وحدة الكنسـول للجانب التطبيقى بخطوط مسـتوحاه من

قرص الثـمس فى الحضـارة المصـرية القديمة لأن حضـارتناو هويتنا المصـــرية من أجمل و أعرق الحضــــار ات ، وهو يبدو كمر آة ملحقة

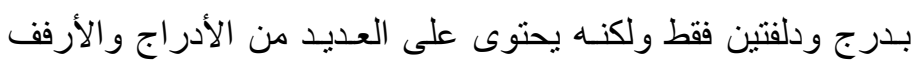
و الدلف السرية ..
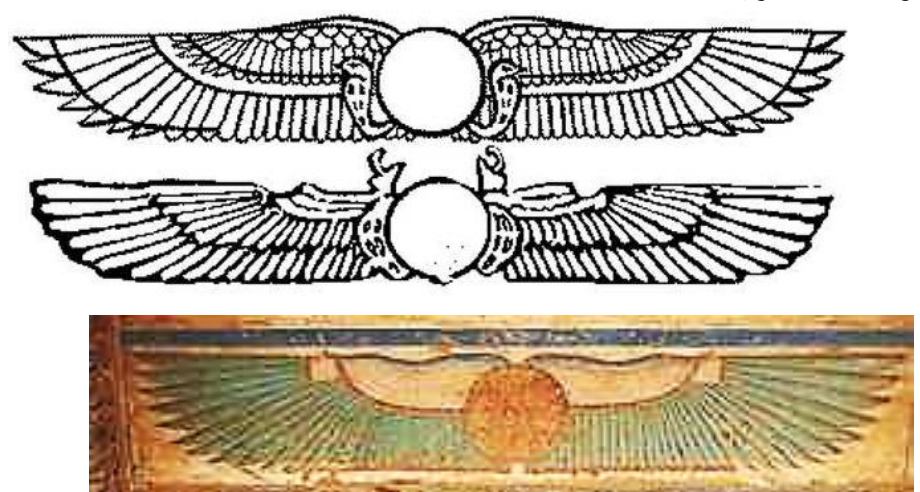

وفيما يلى أماكن تواجد الأدراج والالف السرية فى التصميم:

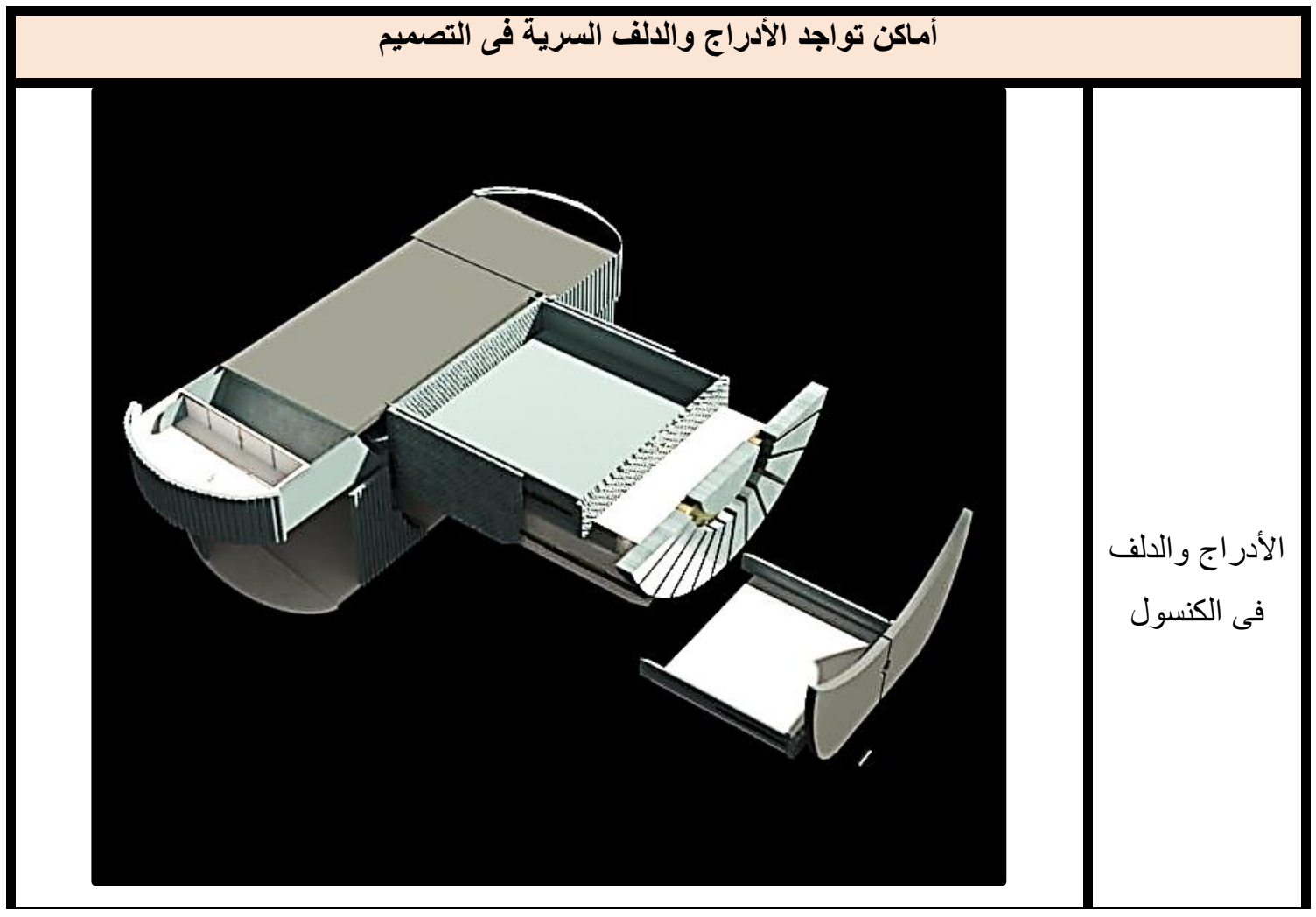




$$
\text { فبر اير r r r T }
$$

مجلة التراث والتصميم ـ المجلد الثاني ـ العدد السابع

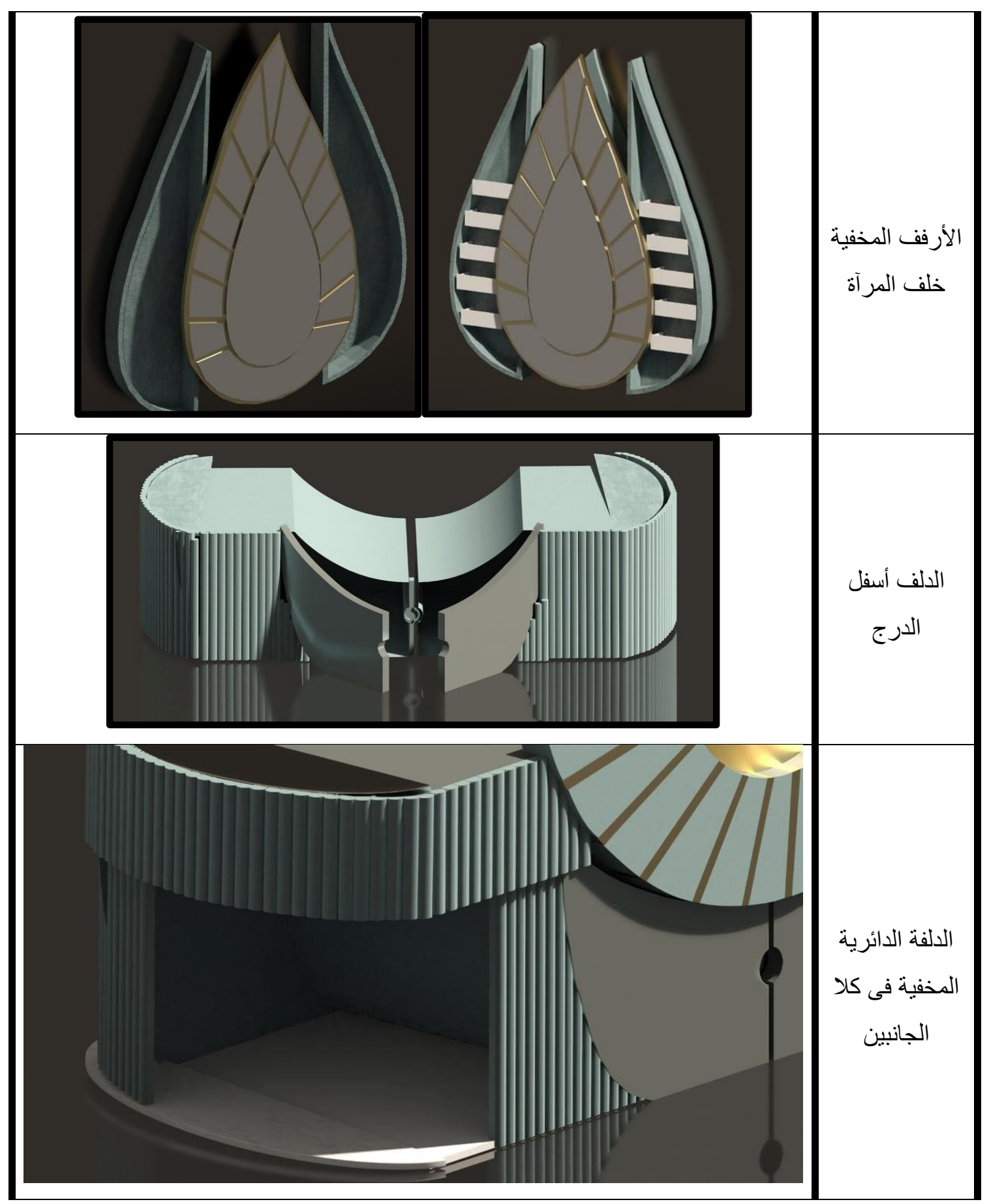



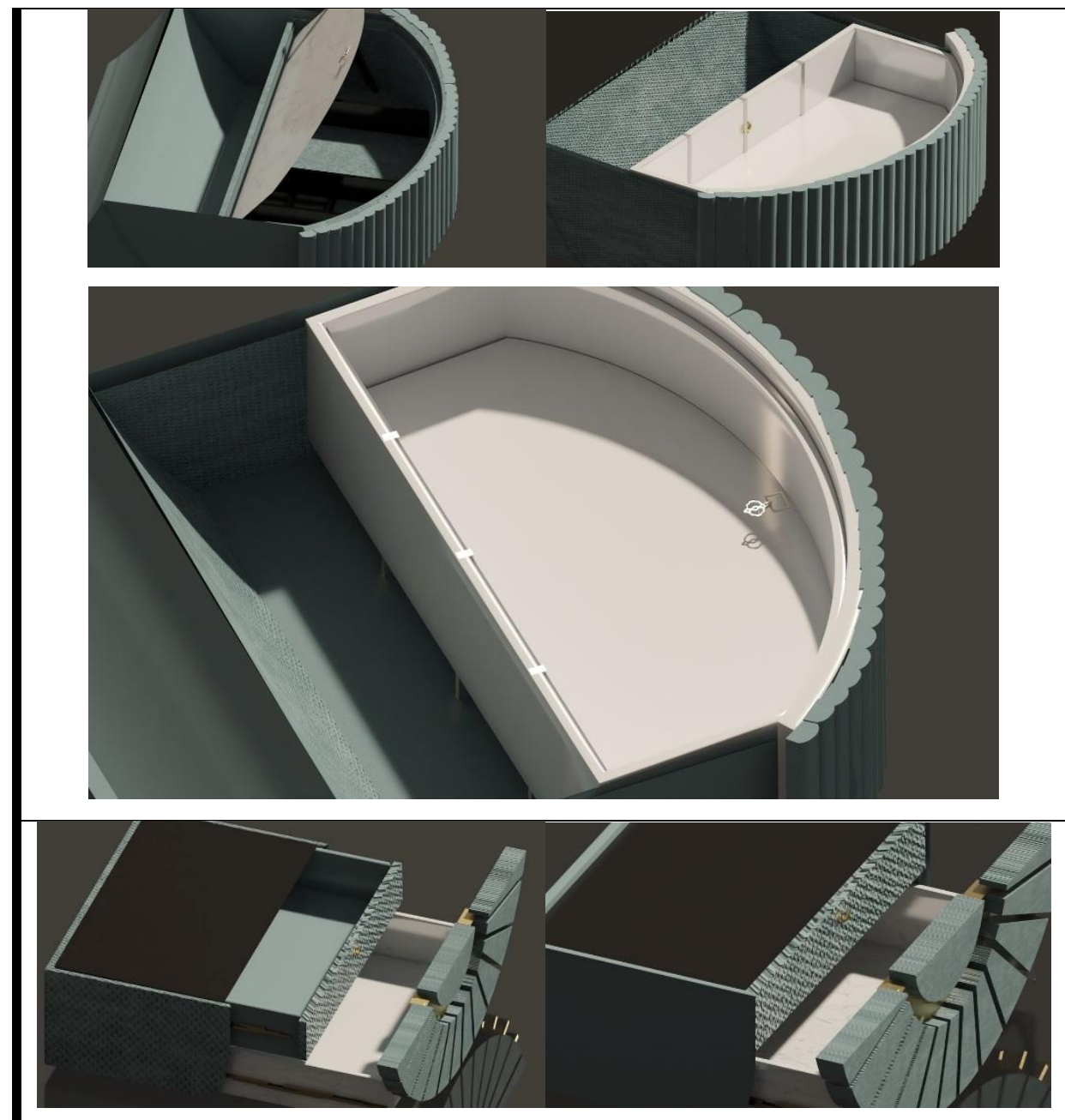

الدرج السري

المخفى خلف

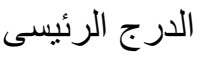

فى الكنسول

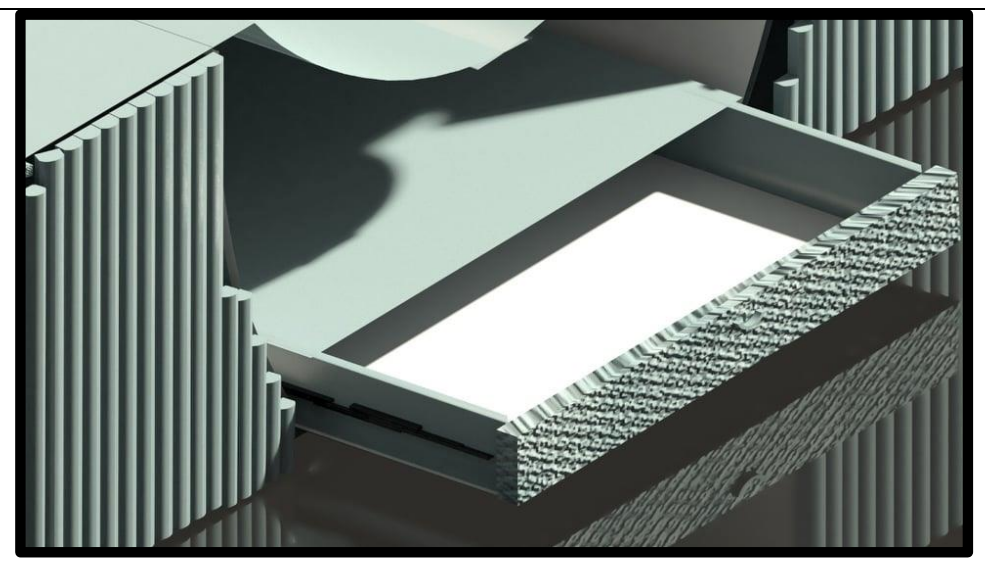

الدرج السري

السفلى

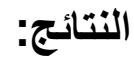

• إن الأثاث والغرف السرية هى مساحات إبداعية آمنة تلبى العديد من الإحتياجات الوظيفية المتنوعة داخل الفراغ، وتساعد فى تأمين راحة الأفر اد ومقتنياتهم الثمينة و الهامة.

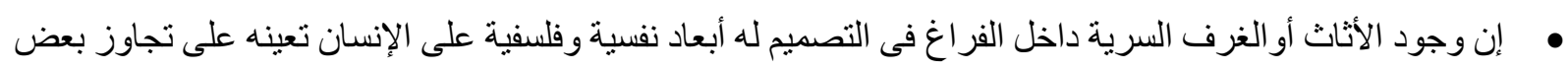
المعوقات الحياتية، وهى تجسيداً لعبارة "أكثر مما تر اه العين". 


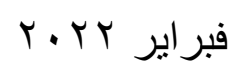$$
\text { مجلة التراث والتصميم - المجلد الثاني ـ العدد السابع }
$$

إن توظيف استخدام الأثاث و الغرف السرية يوفر عنصر الخصوصية والراحة والثعور بالأمان لثاغلى المكان. إن الأثاث و الغرف السرية تساعد فى تعظيم الإستفادة من المساحات الداخلية وإخفاء العيوب داخل التصميم.

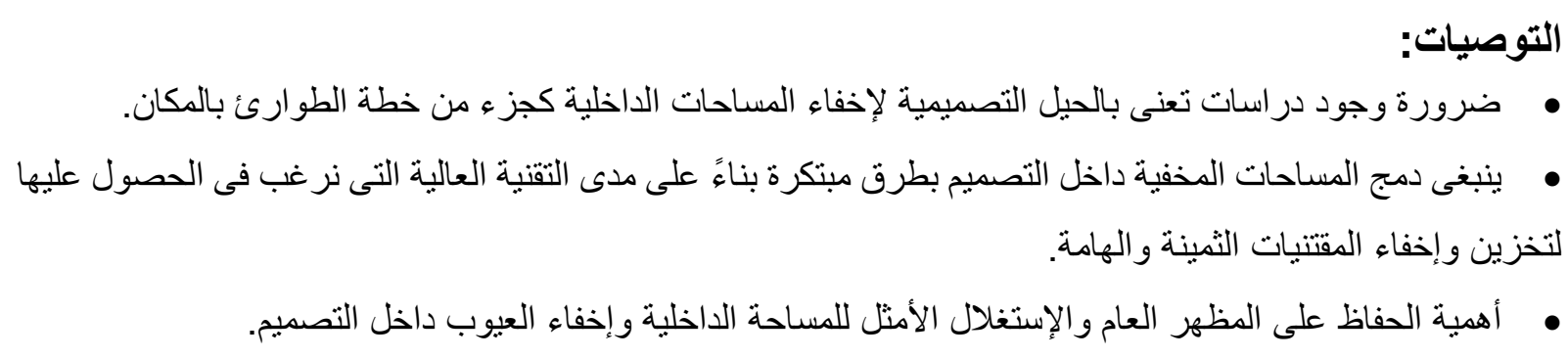

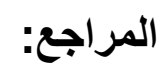

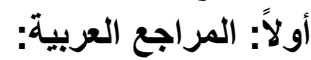
1. سمير، أحمد (د): "مفهوم المرونة في التصميم الداخلى من خلال منظومة التفكير الإبداعى" ـ دكتور اه ــ كلية الفنون

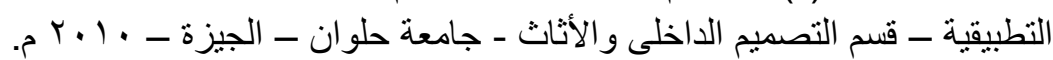
Samir, Ahmed (Dr.): "Mafhom almorona fe altasmem aldakhily men khelel manzomat alfekr al-ebdaey" - Doctora - Kolyat alfenon altatbeea - Kesm altasmem aldakhely wa alathath - Gameat Helwan - Giza - 2010. 2. ر أفت، على (د): دورات الإبداع المعمارى ـ "المضدون و الثكل بين العقلانية والوجدانية" ـ ثناثية الإبداع المعمارى

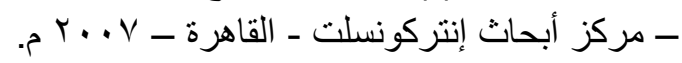
Rafat, Ali: "Dawarat alfekr alebaey - Almadmon wa alshakl bayna alaklanea we alwagdaneya" - tholatheyat alebaa almemary - markaz abhath interkonselt - alkahera

3. Beronich, Carol: "Built-In Secret Spaces" - Article, Wood Smith Magazine - June, 13 2019, available at: https://www.woodsmith.com/article/built-in-secret-spaces/

4. Bridgman, Anthony: "Finding Hidden Storage in Antique Furniture" - westland london UK - 29 March 2019, Online version at: https://www.westlandlondon.com/articles/view,finding-hidden-storage-in-antiquefurniture_35.aspK

5. Chudleigh, Joel: "How 17th Century pirates influenced modern concealment Furniture" MADE TO LAST Online Magazine - UK - February 25, 2020, available at: https://www.madeto-last.co.uk/blog/17th-century-pirates-influenced-modern-concealment-furniture/

6. Margolies, Jane: "If Only These Walls (and Bookcases) Could Talk" - The New York Times Magazine - New York - USA, Aug. 13, 2019 - Online version at: https://www.nytimes.com/2019/08/13/business/if-only-these-walls-and-bookcases-couldtalk.html

7. Monico, Andra Del: “Top 50 Best Hidden Door Ideas - Secret Room Entrance Designs" Next Luxury magazine - July 2021, Online version at: https://nextluxury.com/homedesign/hidden-door-ideas/

8. Sprance, Ryan: "33 Amazing Secret Rooms You Will Want in Your Home" - Article - The Stylish Man Magazine - February,2018, Online version at: http://thestylishman.com/2018/02/33-amazing-secret-rooms-you-will-want-in-your-home/ 
9. Stout, Dan: "10 Incredible Hidden Rooms" - Article - Family Handyman Magazine - Eagan, Minnesota, USA - Jun. 02, 2021- Online version at: https://www.familyhandyman.com/list/10incredible-hidden-rooms/

10. https://en.wikipedia.org/wiki/Secret_passage

ثالثاً: صفحات شبكة الإنترنت:

11. https://www.soss.com/the-history-of-the-secret-rooms/

12. https://ar.aviarydecor.com/2310-hidden-doors-modern-design-solution.html

13. https://theownerbuildernetwork.co/ideas-for-your-rooms/secret-rooms/

14. https://www.boredpanda.com/secret-rooms-hidden-

doors/?utm_source=google\&utm_medium=organic\&utm_campaign=organic

15. https://www.loveproperty.com/gallerylist/76716/35-curious-homes-with-secret-roomshidden-inside

16. https://hiddenpassageway.com/gallery/

17. https://www.indiamart.com/proddetail/space-saver-furnitures-6149662891.html

18. http://www.prayaschildren.org/pro.asp?gj=com\&hl=en\&shop=wall+mounted+cot\&xi=3\& $\mathrm{xc}=28 \& \mathrm{pl}=0 \& \mathrm{pr}=85.99 \& \mathrm{you}=0 \& \mathrm{cid}=129$

19. https://www.livinginashoebox.com/the-dining-table-disappears-into-the-floor-and-thebed-descends-from-the-ceiling-in-this-cool-apartment/

20. https://www.howtodiyeverything.com/how-to-make-secret-compartments-in-furniture/ 21. https://www.stashvault.com/secret-compartment-drawer-rear-of-dresser-furniture/

22. https://qlinedesign.com/concealment-furniture/qline-essentials-nightstand

23. https://americanfurnitureclassics.com/american-furniture-classics-model-433-set-of-twodecorative-wall-shelves-one-with-hidden-gun-concealment-compartment/

\footnotetext{
* في عام VA9 و وفى بداية الثورة الفرنسية هاجم المتظاهرون القصر الملكي في فرساي ولكن الملكة ماري أنطوانيت ملكة فرنسا وزوجة

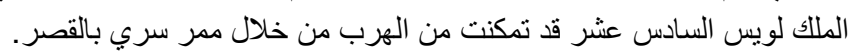

